NATIONAL LABORATORY

\title{
Commercialization of New Carbon Fiber Materials Based on Sustainable Resources for Energy Applications
}

\section{March 22, 2013}

Prepared by

Cliff Eberle

Technology Development Manager

Polymer Matrix Composites

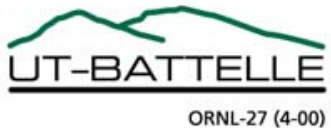




\section{DOCUMENT AVAILABILITY}

Reports produced after January 1, 1996, are generally available free via the U.S. Department of Energy (DOE) Information Bridge.

Web site http://www.osti.gov/bridge

Reports produced before January 1, 1996, may be purchased by members of the public from the following source.

National Technical Information Service
5285 Port Royal Road
Springfield, VA 22161
Telephone 703-605-6000 (1-800-553-6847)
TDD 703-487-4639
Fax 703-605-6900
E-mail info@ntis.gov
Web site http://www.ntis.gov/support/ordernowabout.htm

Reports are available to DOE employees, DOE contractors, Energy Technology Data Exchange (ETDE) representatives, and International Nuclear Information System (INIS) representatives from the following source.

Office of Scientific and Technical Information

P.O. Box 62

Oak Ridge, TN 37831

Telephone 865-576-8401

Fax 865-576-5728

E-mail reports@osti.gov

Web site http://www.osti.gov/contact.html

This report was prepared as an account of work sponsored by an agency of the United States Government. Neither the United States Government nor any agency thereof, nor any of their employees, makes any warranty, express or implied, or assumes any legal liability or responsibility for the accuracy, completeness, or usefulness of any information, apparatus, product, or process disclosed, or represents that its use would not infringe privately owned rights. Reference herein to any specific commercial product, process, or service by trade name, trademark, manufacturer, or otherwise, does not necessarily constitute or imply its endorsement, recommendation, or favoring by the United States Government or any agency thereof. The views and opinions of authors expressed herein do not necessarily state or reflect those of the United States Government or any agency thereof. 
Advanced Manufacturing Office

Commercialization of New Carbon Fiber Materials Based on Sustainable Resources for Energy Applications

\author{
Cliff Eberle \\ Tracy Albers \\ Chong Chen \\ Daniel Webb
}

Date Published: March 2013

Prepared by

OAK RIDGE NATIONAL LABORATORY

Oak Ridge, Tennessee 37831-6283

managed by

UT-BATTELLE, LLC

for the

U.S. DEPARTMENT OF ENERGY

under contract DE-AC05-00OR22725 



\section{Contents}

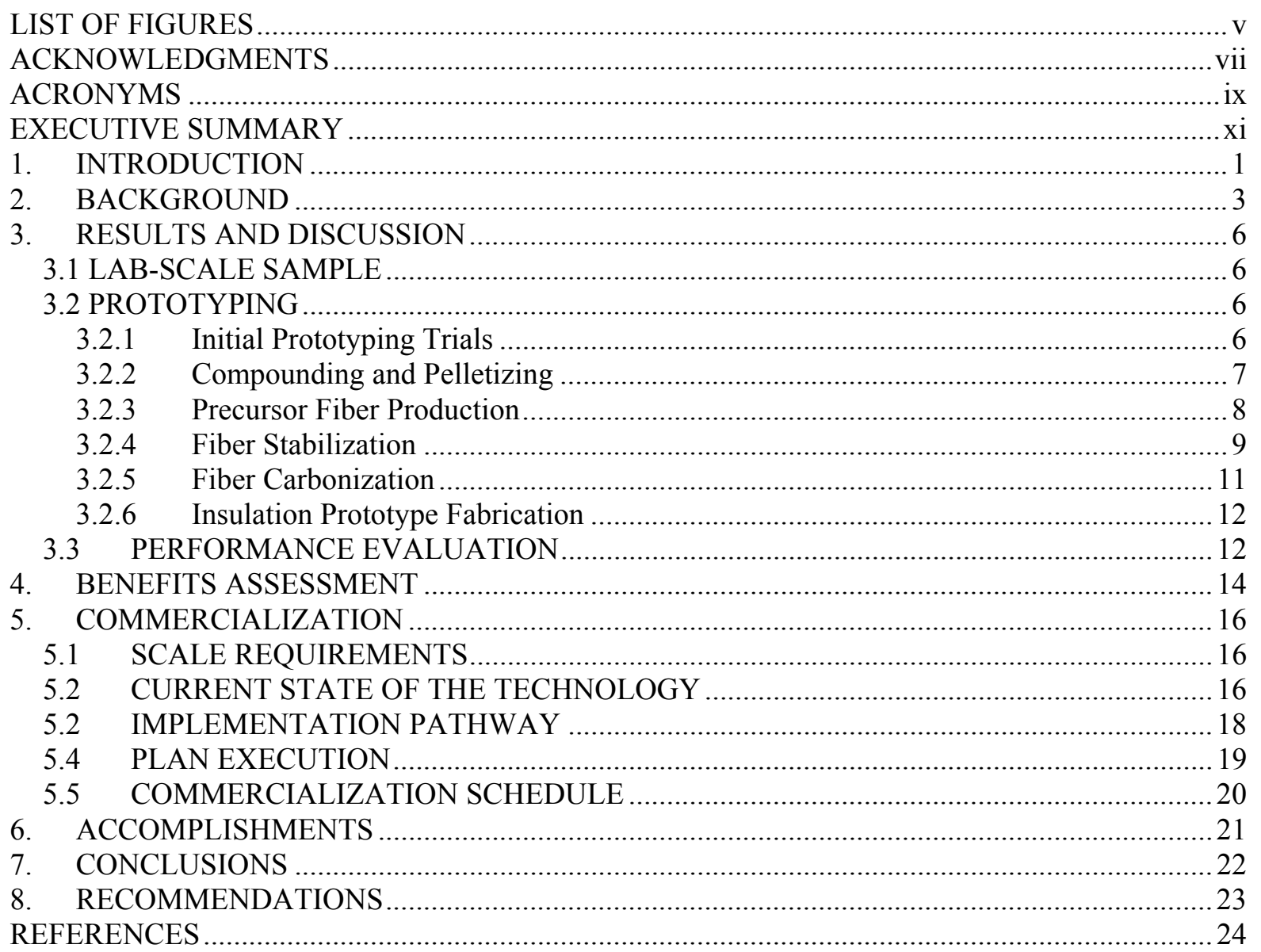





\section{LIST OF FIGURES}

Figure 1. Application of high temperature insulation products: $\mathrm{GRI}^{\mathrm{TM}}$ graphite insulation in a furnace for polysilicon production (left); and various $\mathrm{GRI}^{\mathrm{TM}}$ graphite insulation products machined into

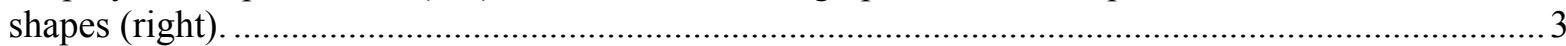
Figure 2. Optical micrograph (under polarized light) of isotropic pitch-based carbon fiber showing no internal structure (left); and anisotropic pitch-based carbon fiber showing a high degree of

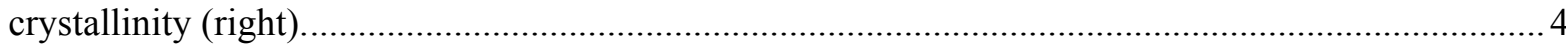

Figure 3. X-Ray Diffraction of anisotropic, isotropic and lignin-based carbon fibers ......................... 4 Figure 4. Bulk GRI ${ }^{\mathrm{TM}}$ graphite insulation board product (left); Micrograph of the internal structure of

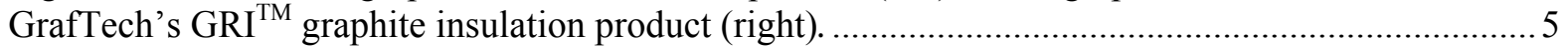

Figure 5. Lignin compounding (left) and pelletizing (right) .................................................... 7

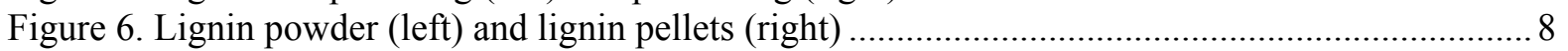

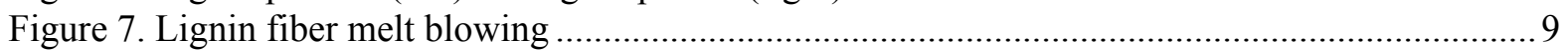

Figure 8. Correlation of lignin stabilization time with glass transition temperature. ......................... 10

Figure 9. Preparing the precursor fiber web for oven charging ................................................... 10

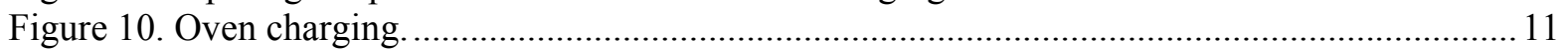

Figure 11. Preparing the stabilized fiber web for shipment to GrafTech ....................................... 11

Figure 12. Milled lignin based carbon fiber (Photo by GrafTech) .................................................. 11

Figure 13. 18" diameter thermal insulation prototypes fabricated from LBCF (GrafTech photo)....... 12

Figure 14. LBCF insulation sections showing uniform structure .................................................... 13

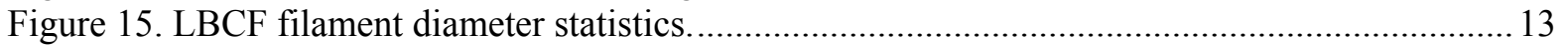

Figure 16. Estimated jobs impact for the production of lignin-based carbon fibers ........................... 14

Figure 17. Time profile of US energy savings attributable to lignin-based carbon fibers .................. 15

Figure 18. Time profile of US $\mathrm{CO}_{2}$ emissions avoidance attributable to low-cost carbon fibers......... 15

Figure 19. Process flow chart for current technology. .................................................................... 16

Figure 20. Estimated production cost of lignin carbon fiber web. .............................................. 17

Figure 21. Estimated correlation of production cost with stabilization time...................................... 18

Figure 22. Summary flow chart of new business development process ............................................ 20 



\section{ACKNOWLEDGMENTS}

This report is based upon work supported by the U. S. Department of Energy under Award Number DE-AC05-000R22725 with the support of the American Recovery and Reinvestment Act (ARRA), and managed by the Advanced Manufacturing Office as CPS Agreement \# 20910, CPS Project \# 20740.

The authors wish to acknowledge the important contributions of our colleagues. Fred Baker served as the ORNL Principal Investigator until he departed ORNL to join a corporate leadership team. Other key ORNL technical contributors included Nidia Gallego, Pol Grappe, Shane Harton, David Jackson, Lex Nunnery, Felix Paulauskas, and Ken Yarborough. Angie Blankenship, Craig Blue, Alan Liby, and Hiram Rogers provided important guidance from the ORNL Advanced Manufacturing Program. Key technical contributors at GrafTech included Bryan Askey, Ryan Freeh, Drew Frerichs, and Dwayne Morgan. Key GrafTech leadership on this project was provided by Lionel Batty and Julian Norley.

Finally, we wish to acknowledge Lignol Innovations for providing multiple tons of Alcell ${ }^{\circledR}$ lignin feedstock for this project. 


\section{ACRONYMS}

$\begin{array}{ll}\text { AG } & \text { Across Grain } \\ \text { ARRA } & \text { American Recovery and Reinvestment Act } \\ \text { Btu } & \text { British Thermal Unit } \\ \text { CFTF } & \text { Carbon Fiber Technology Facility } \\ \text { g/cc } & \text { grams per cubic centimeter } \\ \text { GRI } & \text { Graphite Rigid Insulation } \\ \text { LBCF } & \text { Lignin Based Carbon Fiber } \\ \text { MPa } & \text { MegaPascal } \\ \mu \Omega-m & \text { micro Ohm-meters } \\ \text { ORNL } & \text { Oak Ridge National Laboratory } \\ \text { PAN } & \text { Polyacrylonitrile } \\ \text { PCE } & \text { Polymer Center of Excellence } \\ \text { R\&D } & \text { Research and Development } \\ \text { Tg } & \text { Temperature, glass transition } \\ \text { TPY } & \text { Tons per Year } \\ \text { W/m-K } & \text { Watts per meter-Kelvin } \\ \text { WG } & \text { With Grain } \\ \text { XRD } & \text { X-Ray Diffraction }\end{array}$




\section{EXECUTIVE SUMMARY}

Oak Ridge National Laboratory (ORNL) and GrafTech International Holdings Inc. (GrafTech) have collaborated to develop and demonstrate the performance of high temperature thermal insulation prototypes made from lignin-based carbon fibers. This project will potentially lead to the first commercial application of lignin-based carbon fibers (LBCF). The goal of the commercial application is to replace expensive, Chinese-sourced isotropic pitch carbon fibers with lower cost carbon fibers made from a domestically sourced, bio-derived (renewable) feedstock. LBCF can help recapture jobs that were previously exported to China while resolving supply chain vulnerability and reducing the production cost for GrafTech's high temperature thermal insulation.

The performance of the LBCF prototypes was measured and found to be comparable to that of the current commercial product. During production of the insulation prototypes, ORNL and GrafTech demonstrated lignin compounding/pelletization, fiber production, heat treatment, and compositing at scales far surpassing those previously demonstrated in LBCF R\&D or production.

A plan was developed for the commercialization of LBCF thermal insulation, with key milestones including evaluation of multiple scalable lignin sources in 2013, tons-scale production and field testing by customers in 2014, and product launch as soon thereafter as production capabilities can be constructed and commissioned. 


\section{INTRODUCTION}

Carbon fibers are low density materials that can be tailored to deliver desirable performance in many energy applications. They are most commonly engineered with extreme mechanical performance for structural applications. A typical industrial grade carbon fiber is $16 \mathrm{X}$ stronger, $20 \%$ stiffer, and $4 \mathrm{X}$ less dense than ASTM A36 steel that is commonly used in building and bridge construction. Additionally, carbon fibers can be engineered with low thermal expansion for dimensional stability, high or low thermal conductivity for thermal management, extreme surface area for sorbents, and high electrochemical performance for battery electrodes. Commercial carbon fibers are currently made almost exclusively from petroleum-derived precursors. Industrial grade carbon fibers range in price from approximately $\$ 10 / \mathrm{lb}$ - $\$ 25 / \mathrm{lb}$, depending on the precursor, oil price, and supply-demand balance in the carbon fiber market. Aerospace grade fibers tend to be considerably more expensive (approximately $\$ 25 / \mathrm{lb}-\$ 1,000 / \mathrm{lb}$ ) due to extreme performance requirements, qualification/certification costs, and low production volumes. Precursor fiber cost, when adjusted for yield, comprises about half of the production cost for industrial grade carbon fibers made from polyacrylonitrile (PAN) ${ }^{1}$. Some pitch-based carbon fibers are similarly sensitive to precursor cost. In 2012, global carbon fiber production was estimated to be 66,000 tonnes, of which more than $96 \%$ was structural fibers made from PAN. ${ }^{2}$

Today, the carbon fiber market is a niche market, largely due to high price. The development of new technologies enabling lower cost production can enable penetration into high volume, cost-sensitive energy applications ${ }^{3}$. One very attractive technology pathway is the development of lower cost precursors that are decoupled from the oil market. Lignin, "the glue that holds trees together," is an inexpensive, high-carbon by-product of pulp and paper production as well as biorefineries. The available lignin resource is enormous. Up to 40 million tonnes/year can potentially be isolated from the world's Kraft pulp mills without adversely impacting mill operations. ${ }^{4}$ Lignin offers very high potential to reduce carbon fiber $\operatorname{cost}^{5}$, but to date the achievement of good mechanical properties in lignin-based carbon fibers (LBCF) has proven elusive. Conversely, lignin naturally tends to exhibit characteristics that can be exploited in certain functional (nonstructural) applications.

The objective of this project was to develop and scale LBCF for one or more applications for which its readily achievable properties are acceptable. Applications considered included:

- High temperature thermal insulation - many high temperature furnaces, such as those used for manufacturing solar photovoltaic materials, sapphire crystal and light emitting diodes, use thermal insulation made from isotropic pitch-based carbon fibers. Thermally insulating carbon fibers can readily be produced from lignin while delivering significant cost advantage vs. isotropic pitch-based carbon fibers.

- Electric arc furnace graphite electrodes - reinforcement of these electrodes results in longer life and reduces steel foundry energy use by up to $5 \%$. The very modest mechanical properties that have been demonstrated in LBCF are adequate for market entry if the fiber price is sufficiently low.

- Advanced energy storage systems - nanoporous (activated) carbon is the dominant material in electrodes for advanced energy storage systems (ultracapacitors and asymmetric battery/capacitor devices), but the high-activity materials required are currently far too expensive for large-scale applications; e.g., plug-in hybrid vehicles, water treatment, wind and solar power. Low-cost nanoporous carbon materials can potentially be produced from renewable, lignin-based sources. 
The key industrial partner involved in this project is GrafTech International Holdings Inc., a global company with more than 125 years in the graphite materials industry, operating 20 principal manufacturing facilities on four continents and employing more than 3,000 people. GrafTech happens to be the original inventor of high performance carbon fibers, although it divested that business decades ago and currently purchases carbon fibers for use in "downstream" manufactured products.

GrafTech has existing product lines in the application areas considered: thermal insulation, graphite electrodes, and energy storage. Early in the project, GrafTech and ORNL chose to focus on the thermal insulation application. Thermal insulation was judged to offer the highest probability of technical success in the shortest time and also addressed a key supply chain issue - high price and uncertain availability of the carbon fibers used to manufacture GrafTech's GRAFSHIELD GRI ${ }^{\mathrm{TM}}$ insulation product line.

To demonstrate the potential for insulation made from LBCF, ORNL and GrafTech produced and evaluated insulation samples about the size of a hockey puck and then $\sim 18$ " diameter $\mathrm{x} 10$ " thick. At both scales, the performance of the LBCF insulation was similar to that of the commercial product. The manufacturing of the larger sample required pelletizing, spinning, stabilizing, carbonizing, molding, and graphitizing at scales well beyond the previous scales for production or use of LBCF.

The major short-term national impact of the thermal insulation application is the recapture of jobs that were exported to China. Longer term, the early success can enable continued development of LBCF technology and penetration into large energy applications resulting in thousands of U.S. jobs with annual energy and environmental impacts of tens of trillions of Btu's energy savings and millions of tonnes of $\mathrm{CO}_{2}$ emission avoidance. Additionally, LBCF deployment will create a new market for lignin from biorefineries, thus improving their economics.

Key milestones in the commercialization plan include qualification of multiple scalable lignin sources in 2013, tons-scale production and field testing by customers in 2014, with product launch as soon thereafter as production capabilities can be constructed and commissioned. 


\section{BACKGROUND}

In the past several decades, carbon fiber has been mainly used for structural reinforcement in the composite materials industry. However, carbon fiber can also be used for functional (nonstructural) applications, in which the strength is not a key criterion, and other properties, e.g., thermal and electrical, are utilized instead. Based on the microstructural characteristics of the carbon fiber, it can be either conductive or non-conductive (thermally insulating). Carbon fiber is a unique material, withstanding $3000{ }^{\circ} \mathrm{C}$ or higher temperatures in an inert environment.

The primary objective of this project was to demonstrate and scale LBCF for use in functional applications. Several different applications were considered, but early in the project the team selected high temperature thermal insulation as the focal application for the project. This selection was based on preliminary data suggesting that LBCF could be readily produced with the required properties and a significant cost advantage. For the thermal insulation application, thermal conductivity is a main criterion and a non-thermally conductive carbon fiber is required. GrafTech's thermal insulation has been historically produced from isotropic pitch fibers sourced from China. These fibers are considerably more expensive than the projected cost of LBCF. Additionally, the pitch fibers have significant pricing and supply volatility. For thermal insulation, LBCF can potentially resolve supply chain vulnerability, reduce production cost, and be quickly introduced into the market as an alternative raw material used to manufacture an existing product.

First attempts to develop LBCF date to the late 1960's. ${ }^{6}$ In recent years, ORNL and several other research institutes have revisited the potential to use lignin as a precursor for structural carbon fibers. While significant advancements have been made in processing lignin, state-of-the-art mechanical properties have not improved significantly. ${ }^{7}$ However, lignin is readily amenable to processing and properties that are needed for certain functional (nonstructural) applications. The project team has exploited these lignin attributes to develop and evaluate thermal insulation prototypes.

GrafTech's GRAFSHIELD GRI ${ }^{\mathrm{TM}}$ graphite insulation is used in the renewable energy industry, in multiple crystal growing furnace applications, including sapphire and LED's. GRI ${ }^{\mathrm{TM}}$ graphite insulation is also utilized in many additional high temperature insulation applications, for the production of plastics, chemicals and other industrial materials. Figure 1 shows the application of GRI ${ }^{\mathrm{TM}}$ graphite insulation in the production of polysilicon (left) and various thermal insulation products (right). GrafTech's GRI ${ }^{\mathrm{TM}}$ insulation product is made from isotropic carbon fibers.

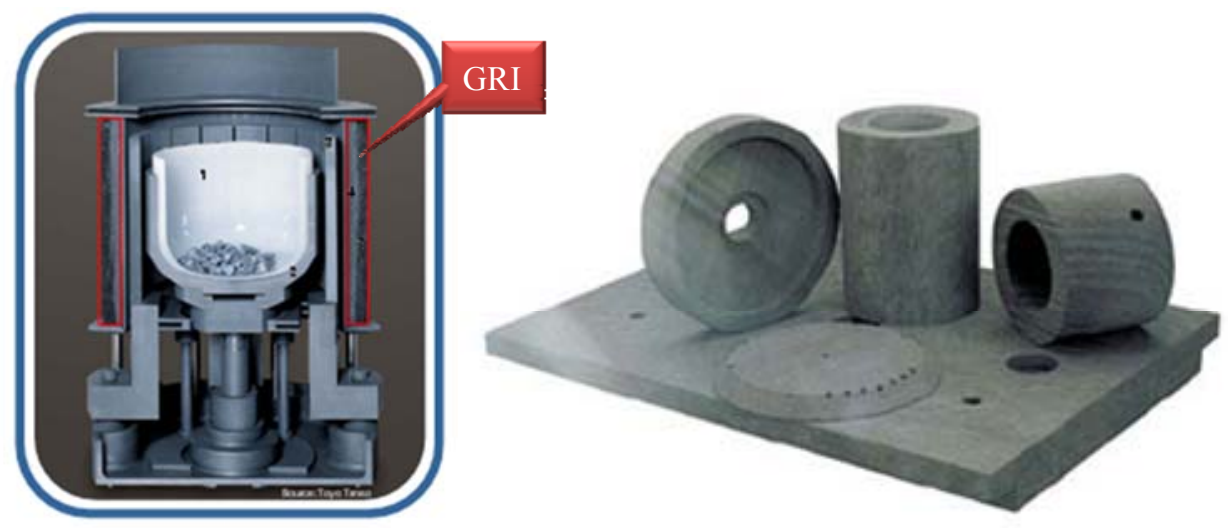

Figure 1. Application of high temperature insulation products: GRI ${ }^{\mathrm{TM}}$ insulation in a furnace for polysilicon production (left); and various GRI ${ }^{\mathrm{TM}}$ insulation products machined into shapes (right). 
Figure 2 depicts the optical micrographs of two different types of carbon fibers: isotropic (left) and anisotropic (right). The anisotropic carbon fiber shows structural alignment along the fiber axis while the isotropic carbon fiber does not show an ordered structure. The X-ray diffraction (XRD) analysis (Figure 3 ) of the corresponding materials confirms the microstructural characteristics. The presence of an aligned or ordered structure (increased crystallinity) translates to a high degree of thermal conductivity, an undesirable attribute for use in a thermal insulation product. The LBCF has a disordered structure, which translates to a low thermal and electrical conductivity, suggesting ideal applicability as an insulating medium.
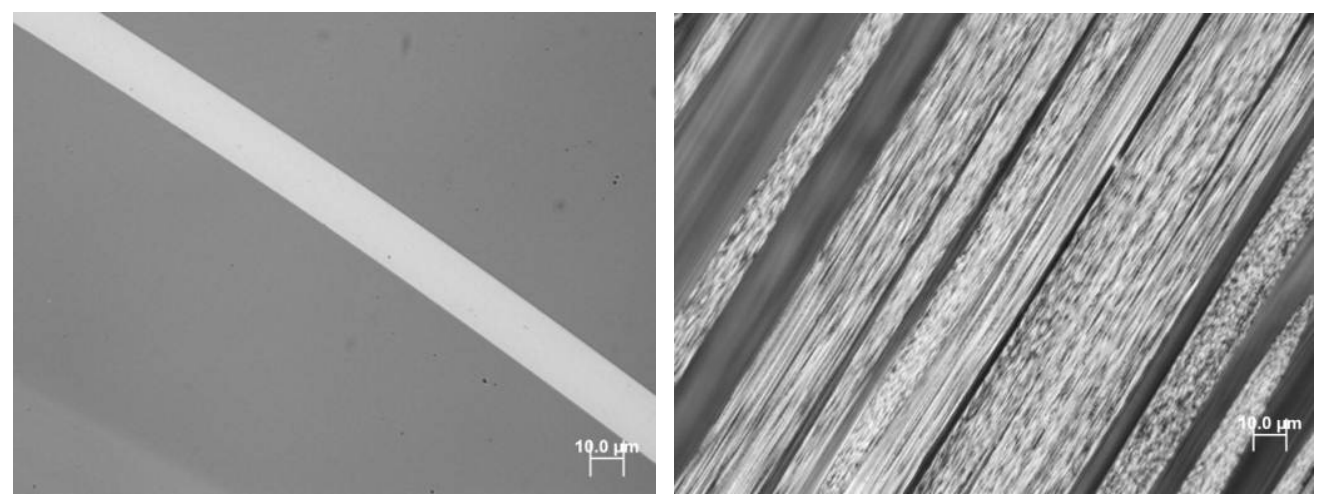

Figure 2. Optical micrograph (under polarized light) of isotropic pitch-based carbon fiber showing no internal structure (left); and anisotropic pitch-based carbon fiber showing a high degree of crystallinity (right).

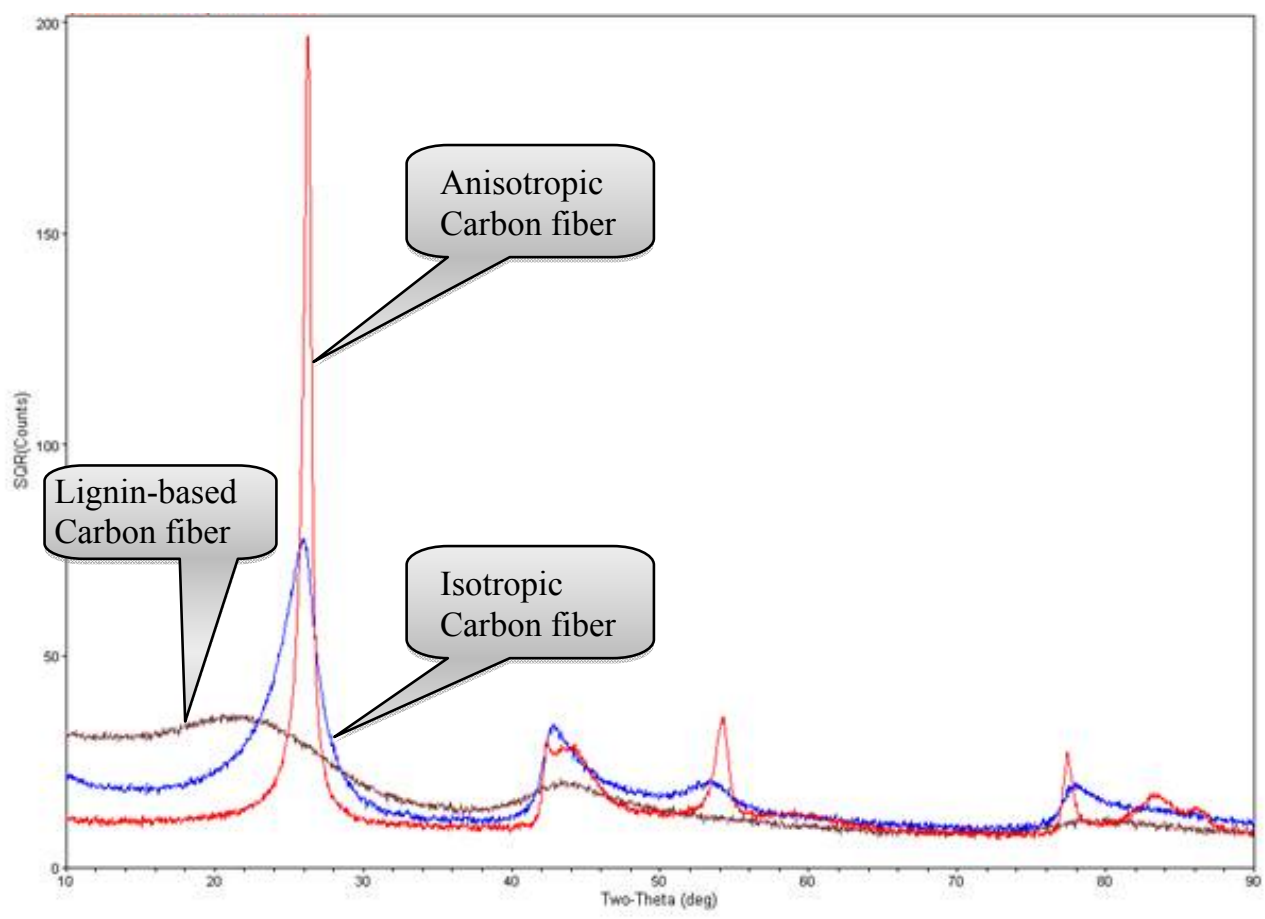

Figure 3. X-Ray Diffraction of anisotropic, isotropic and lignin-based carbon fibers. 
For use in GrafTech's GRI ${ }^{\mathrm{TM}}$ graphite insulation product, the carbon fiber is used as a raw material to form a rigid insulation board as shown in Figure 4. The thermal conductivity in the through-thickness direction is the most critical property for this application. The microstructure of LBCF, as indicated in Figure 3, suggested that it was likely to exhibit the thermal conductivity required for GRI ${ }^{\mathrm{TM}}$ graphite insulation.
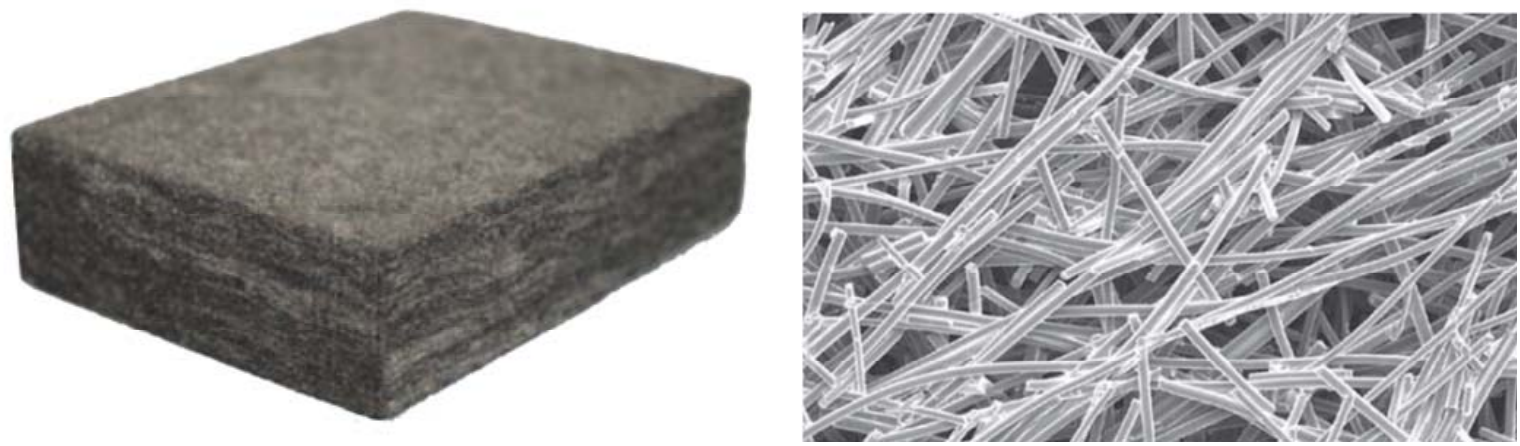

Figure 4. Bulk GRI ${ }^{\mathrm{TM}}$ graphite insulation board product (left); Micrograph of the internal structure of GrafTech's GRI ${ }^{\mathrm{TM}}$ product (right).

To validate the potential of LBCF to be used in the production of GRI ${ }^{\mathrm{TM}}$ graphite insulation, ORNL and GrafTech chose to make and test GRI ${ }^{\mathrm{TM}}$ graphite insulation samples. The first samples would be laboratory samples about the same size as a hockey puck. This would be followed by the production and testing of full-scale insulation boards, which would require approximately $200 \mathrm{lb}$. (net) of LBCF per board. 


\section{RESULTS AND DISCUSSION}

\subsection{LAB-SCALE SAMPLE}

The first task in this project was the production and evaluation of a thermal insulation sample about the size of a hockey puck (roughly 4" diameter and 1" thick). For this application ORNL produced 12 x 25 gram batches, totaling 300 grams of LBCF which were sent to GrafTech for evaluation. Throughthickness conductivity of the LBCF puck was measured at $0.18 \mathrm{~W} / \mathrm{m}-\mathrm{K}$, vs. $0.18 \mathrm{~W} / \mathrm{m}-\mathrm{K}$ in the standard product. Tests also indicated that structural integrity satisfies the requirements for the GRI ${ }^{\mathrm{TM}}$ graphite insulation manufacturing and service environments. Therefore it was decided to proceed to the next scale.

\subsection{PROTOTYPING}

The initial prototyping plan was to produce at least two full-scale insulation boards. Each board requires about $200 \mathrm{lb}$ of carbon fiber. Therefore the initial plan was to produce $500-1,000 \mathrm{lb}$ of LBCF from Alcell $^{\circledR}$ lignin, which would include ample allowance for scrap. However, during the project GrafTech developed a new subscale insulation prototyping capability, enabling them to manufacture 18 " diameter prototypes which required only $20 \mathrm{lb}$ of carbon fiber per prototype. This reduced the amount of LBCF required to $50-100 \mathrm{lb}$. Nevertheless during most of the project, it was unclear whether this capability would be available on the required schedule, so the team worked toward the larger production target until the prototyping capability came online.

The relative quantities of material produced in each production step are not indicative of yield. In every step except carbonization, considerably more product was made than was necessary for the following step.

\subsubsection{Initial Prototyping Trials}

Because ORNL did not have the capability to compound, pelletize, or spin fibers at the required scale' this work was subcontracted. ORNL will have the capability to compound, pelletize, and spin fibers at this scale after the Carbon Fiber Technology Facility commences operation in March or April 2013. The initial semi-production scale lignin compounding and pelletization was attempted at the Polymer Center of Excellence (PCE) in Charlotte, NC with fiber spinning at Hills, Inc. in Melbourne, FL. The operation was significantly constrained by narrow windows of equipment availability. Because it was not practical in the timeframe involved to carry out two separate steps at different and widely separated locations, the first steps of lignin heat treatment and pelletization were combined into a single operation using twin screw compounding/pelletizing equipment at PCE with the capability to devolatilize the lignin through vacuum venting ports on the extruders. This is an approach that would be used on a commercial scale, but had not been evaluated and demonstrated on either lab or pilot scales. Despite dedicated efforts by PCE over ten days of continuous work, the required level of devolatilization of the lignin was not achieved in the pelletized product; furthermore, the pelletization technique employed resulted in considerable air entrainment in the lignin pellets. These undesirable features of the pelletized lignin became apparent during melt spinning of the lignin fibers at Hills, which was carried out simultaneously with the production of the pelletized lignin. The entrained air and inadequate devolatilization of the lignin impacted the spinning operation, resulting in rupture of the fragile, $\sim 10$ micron diameter fibers as they emerged from the spinneret. Many different approaches were tried to overcome the problem, including changes in the pelletizing operation at PCE and reconfiguration of spin packs on the spinning 
equipment at Hills. Each approach resulted in some improvement but not enough to sustain melt spinning of lignin fibers. The efforts were further complicated by the discovery that feeding relatively large amounts of lignin through the commercial scale melt spinning equipment and over longer periods of time than attempted on the ORNL lab scale equipment plugged the fine mesh filter packs upstream of the spin pack resulting in premature rise in pressure drop across the filter. This necessitated more frequent interruptions of fiber spinning to rebuild the filter and spin packs, operations that required almost 7 hours of downtime. Filter pack plugging was traced to very fine particles (40-70 micron) of sand, which although present in the lignin at trace levels only accumulated in the filter pack with increased time of equipment operation.

Towards the end of the 1-week period of work at Hills, improvements in the lignin pelletization operation and correction of deficiencies with respect to devolatilization, air entrapment, and pre-filtering of the lignin to remove trace levels of sand, resulted in a batch of pelletized lignin (about $45 \mathrm{lb}$ ) that could be successfully melt spun on the Hills equipment using a 344 hole spinneret. Thus, albeit too late to salvage the main objective of the work, scale-up of lignin melt spinning was successfully demonstrated. Batches of the spun lignin fiber were shipped back to ORNL for thermal processing into carbon fiber.

Thermal processing of a small portion of the lignin fiber produced at Hills resulted in poor quality carbon fiber (very fragile) that was not suitable for GrafTech. This confirmed that not only was the devolatilization of the lignin inadequate and that air entrainment had occurred during the pelletization operation, but also that the lignin was prematurely oxidized; i.e., before melt spinning into fiber.

\subsubsection{Compounding and Pelletizing}

Based upon lessons learned at PCE, a new approach was formulated. Compounding trials were conducted at Entek Manufacturing (Lebanon, OR). Entek's twin screw compounding extrusion technology readily reduced moisture and volatiles in the extruded lignin to low and near target levels; this was the critical step that failed in the first scale-up work. Furthermore, using Entek's smallest, $27 \mathrm{~mm}$ extrusion machine, a lignin throughput of $100 \mathrm{lb} / \mathrm{hr}$ was demonstrated.

Semi-production scale lignin pelletization was also done at Entek (Figure 5), A $53 \mathrm{~mm}$ diameter extrusion machine equipped with a hot die face cutter was used to successfully pelletize almost 2,000 lb of lignin for subsequent melt spinning into precursor fiber.
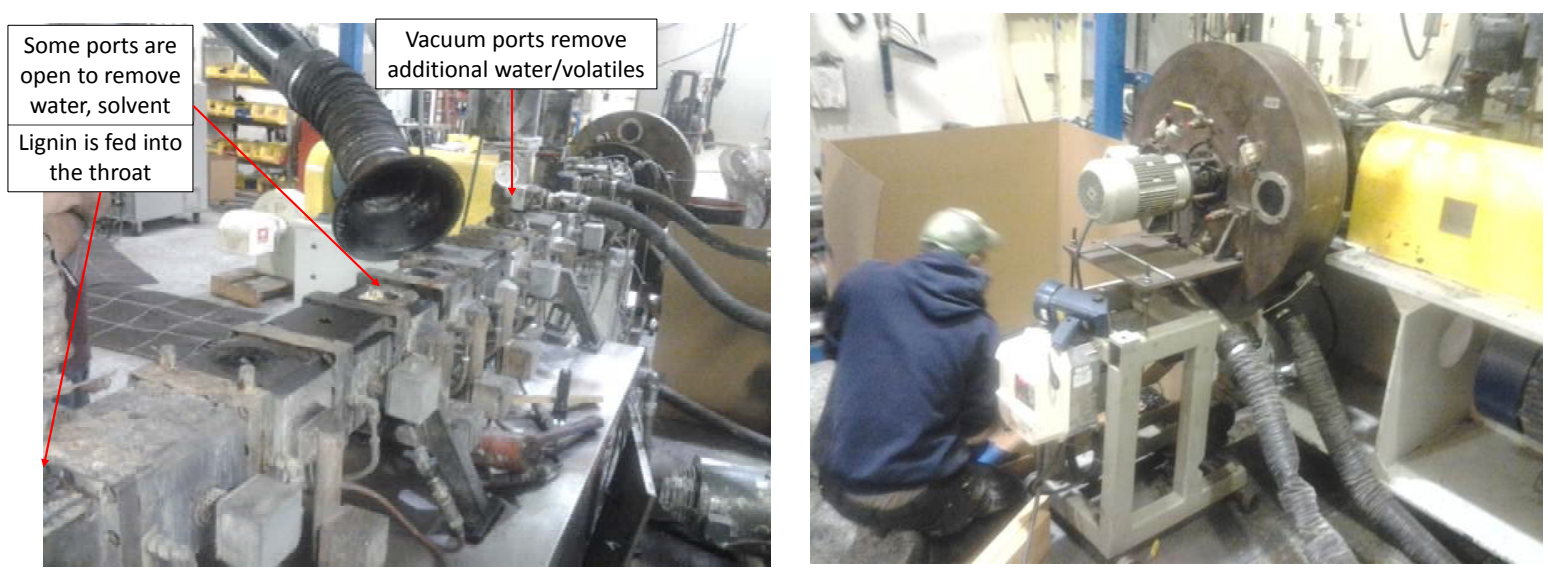

Figure 5. Lignin compounding (left) and pelletizing (right).

Lignin powder feed and pellets are shown in Figure 6. This is the first known production of lignin pellets (satisfying quality requirements for filament extrusion) at the 10-lb scale. 

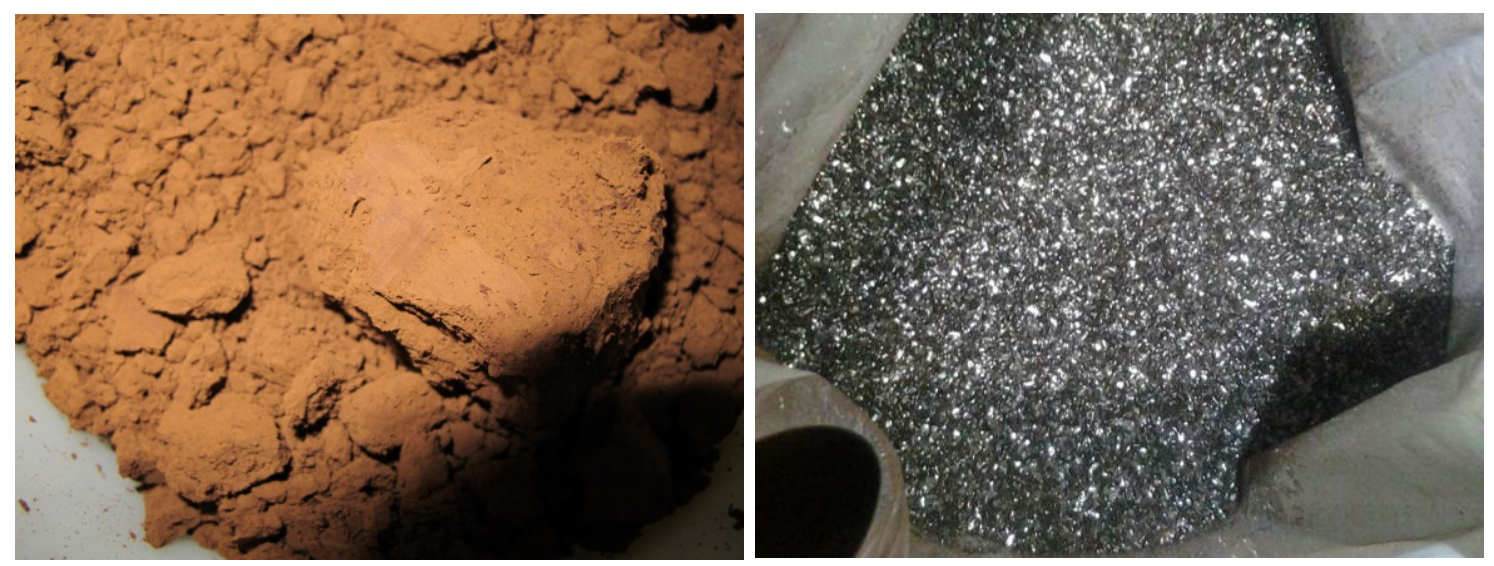

Figure 6. Lignin powder (left) and lignin pellets (right)

\subsubsection{Precursor Fiber Production}

Precursor fiber "semi-production" was completed at Hills, Inc. Using a lab scale machine, both "spun bond" and "melt blown" spinning techniques were evaluated for producing a lignin fiber web with a filament diameter in the range of 10-20 micron. Although both techniques produced good fiber web, it proved difficult to sustain the spun bond spinning. On the basis of the results from this preliminary trial, the production phase of the lignin fiber spinning work was carried out at Hills using a commercial scale machine equipped with melt blowing capability.

During the first semi-production run, lignin fiber web was continuously melt blown over a total time of 16 hours ( 10 hours first day, 6 hours second day) without interruption of spinning or incident during each of the two spinning periods. Throughput on the machine was progressively raised to about $33 \mathrm{lb} /$ hour, which appeared to be close to the maximum capacity for lignin spinning on the machine. Spinning on the second day was terminated after 6 hours when the pressure drop across the filter pack rose to an unacceptable level as the filter blinded, which was the primary criterion for the length of time it was possible to run the machine during the 2-day window of availability. Approximately $400 \mathrm{lb}$ of lignin fiber web with filament diameters in the target range was produced over the two day period. Two more semiproduction runs were completed, each producing about $400 \mathrm{lb}$ of lignin fibers. Other miscellaneous trials, leveraged with other work being done at Hills by ORNL, netted an additional $300 \mathrm{lb}$ of lignin fiber, thus delivering approximately $1,500 \mathrm{lb}$ of melt blown lignin fibers produced in this project. The fibers were spun into a web approximately two feet wide with areal density $\sim 6.8 \mathrm{oz} / \mathrm{sq}$ yd $\left(230 \mathrm{~g} / \mathrm{m}^{2}\right)$ at rates approaching $30 \mathrm{lb} / \mathrm{hr}$.

Lignin fiber production is shown in Figure 7. This is the first known production of lignin fibers at the 10lb scale. 

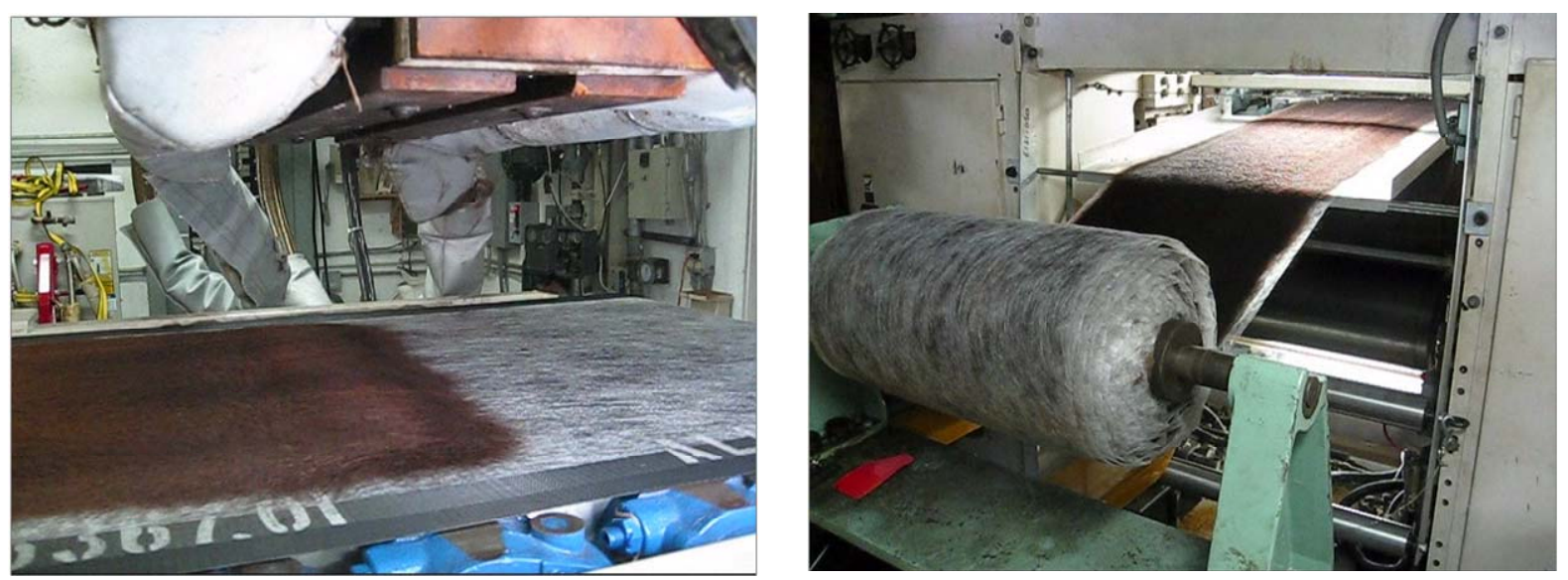

Figure 7. Lignin fiber melt blowing.

The lessons learned from the fiber production trials resulted in the establishment of a "notional" lignin specification for melt spinnable lignin, as follows:

- $>99 \%$ lignin

- $\quad<500$ ppm residual carbohydrates

- $\quad<5 \mathrm{wt} \%$ volatiles

- $\quad<1000 \mathrm{ppm}$ ash

- $\quad<500$ ppm non-melting particles larger than 1 micron diameter

\subsubsection{Fiber Stabilization}

Stabilization time was and remains a significant challenge. For the "reference" Alcell ${ }^{\circledR}$ lignin, the stabilization time requires several days. Stabilization must be accelerated to achieve acceptable process economics.

Softwood lignins tend to stabilize much faster than hardwood lignins, so one way to reduce stabilization time is to simply change to a softwood lignin. However this introduces new challenges because softwood lignins are typically not inherently melt spinnable. A key challenge is to achieve fast stabilization, melt spinning, and required properties all in the same lignin, while maintaining the material's inherent cost advantage.

One proven method of decreasing stabilization time is devolatilization prior to melt spinning, which has been practiced regularly in the lab at ORNL in a batch process, in which lignin is vacuum-baked in laboratory ovens. Such a process is effective at decreasing the duration of stabilization for pound quantities. However, it is unsuitable to deliver the quantities of lignin that were required for this scale-up (hundreds of pounds).

Significant gains were made on the processing of lignin prior to fiber formation. Multiple-passing through the compounding extruder was shown to increase the softening point of lignin, which results in significant decreases in stabilization time. Figure 8 compares the stabilization time of lignin fibers vs. their glass transition temperature. As can be seen from the data points, from data collected at ORNL on a laboratory-scale, an increase in glass transition temperature by devolatilization results in significant improvements in further processing time. We were able to partially achieve similar levels of devolatilization in Entek's 53-mm compounding extruder at $\sim 100 \mathrm{lbs} / \mathrm{hr}$. 


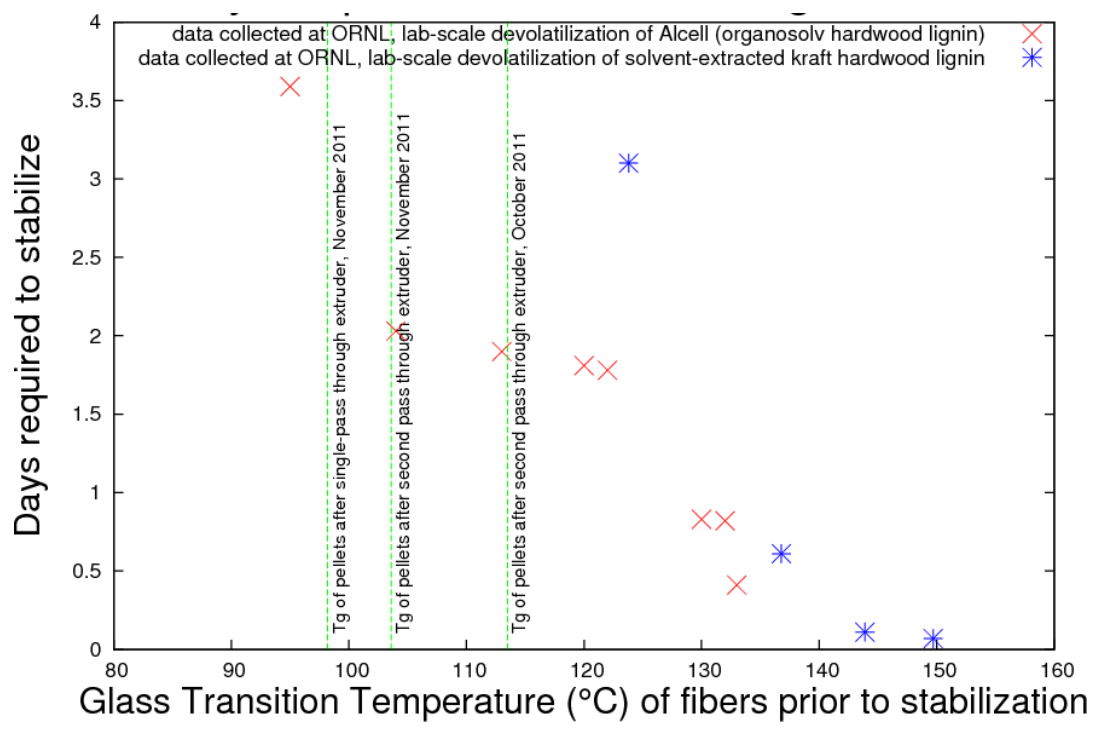

Figure 8. Correlation of lignin stabilization time with glass transition temperature.

In another project, ORNL recently demonstrated further reduction of stabilization time to $\sim 10$ hours by a scalable, $\sim 2$-hr devolatilization process. The devolatilization equipment currently available is limited to $\sim$ 1 -lb batch sizes. Furthermore budget and schedule constraints did not allow us to pelletize or spin semiproduction quantities of material after the devolatilization process was demonstrated. Therefore to accomplish the objectives of this project we deferred scalable, fast stabilization for future development.

A simple tuning of the thermal profile reduced the residence time from $\sim 150$ hours to $\sim 100$ hours. There were several iterations to optimize the thermal profile, each including sending stabilized fibers to GrafTech to be evaluated for processibility in the carbonization step. After ORNL and GrafTech settled on the protocol, ORNL stabilized fibers using a $\sim 100$-hr batch thermal treatment in a large $\left(>200 \mathrm{ft}^{3}\right)$ oven. $180 \mathrm{lb}$ of lignin fibers were stabilized and shipped to GrafTech for further processing and prototype fabrication. This is the first reported stabilization of lignin fibers at a scale exceeding $\sim 1 \mathrm{lb}$. Various steps in the batch stabilization operation are shown in Figures $9-11$.
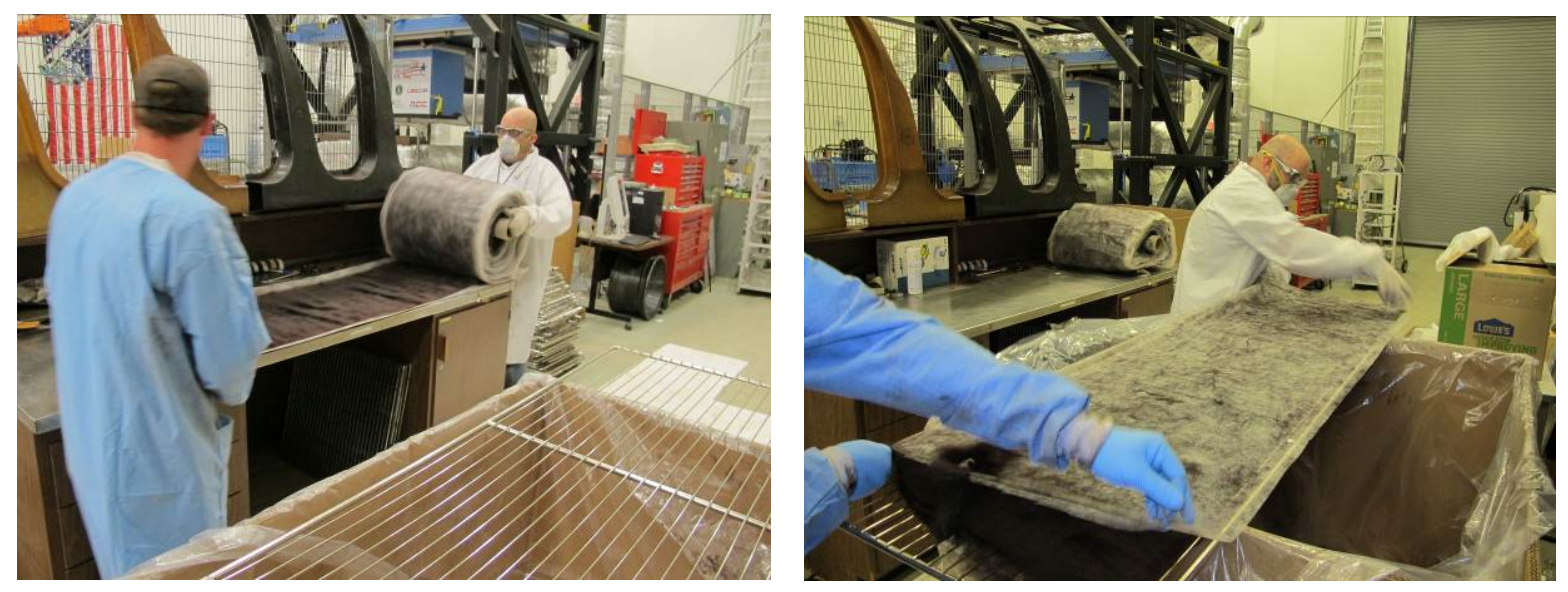

Figure 9. Preparing the precursor fiber web for oven charging. 

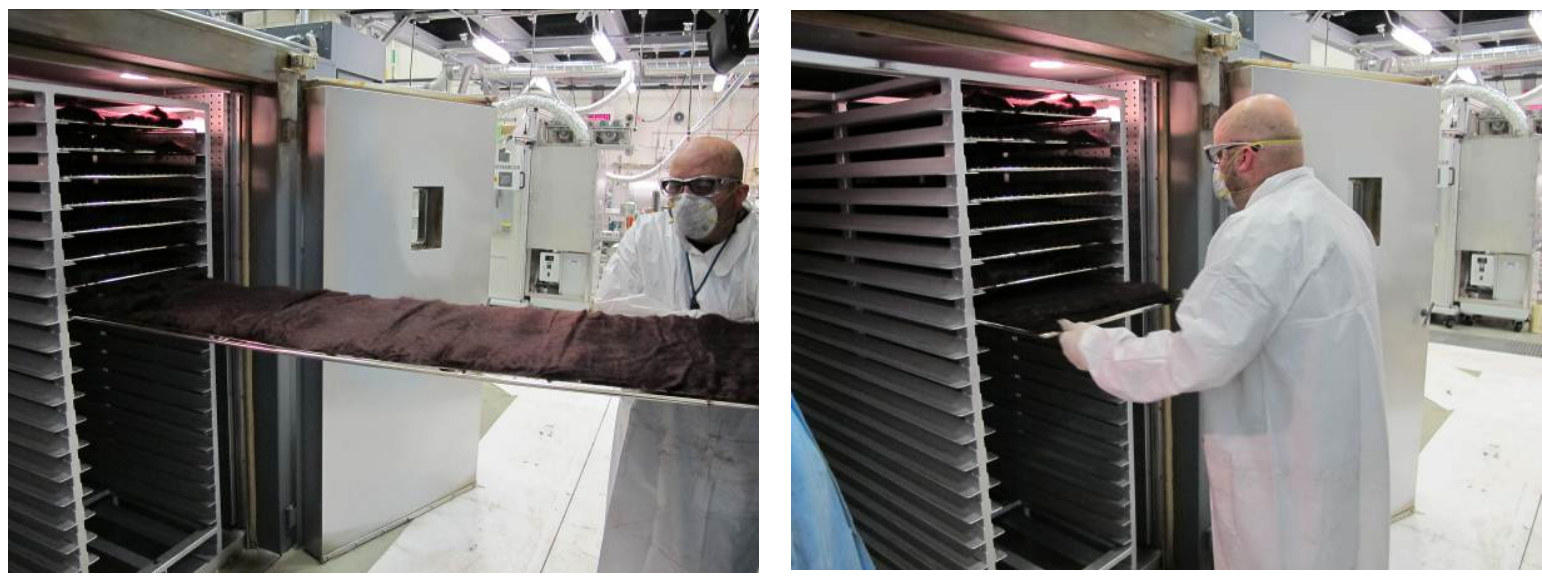

Figure 10. Oven charging.
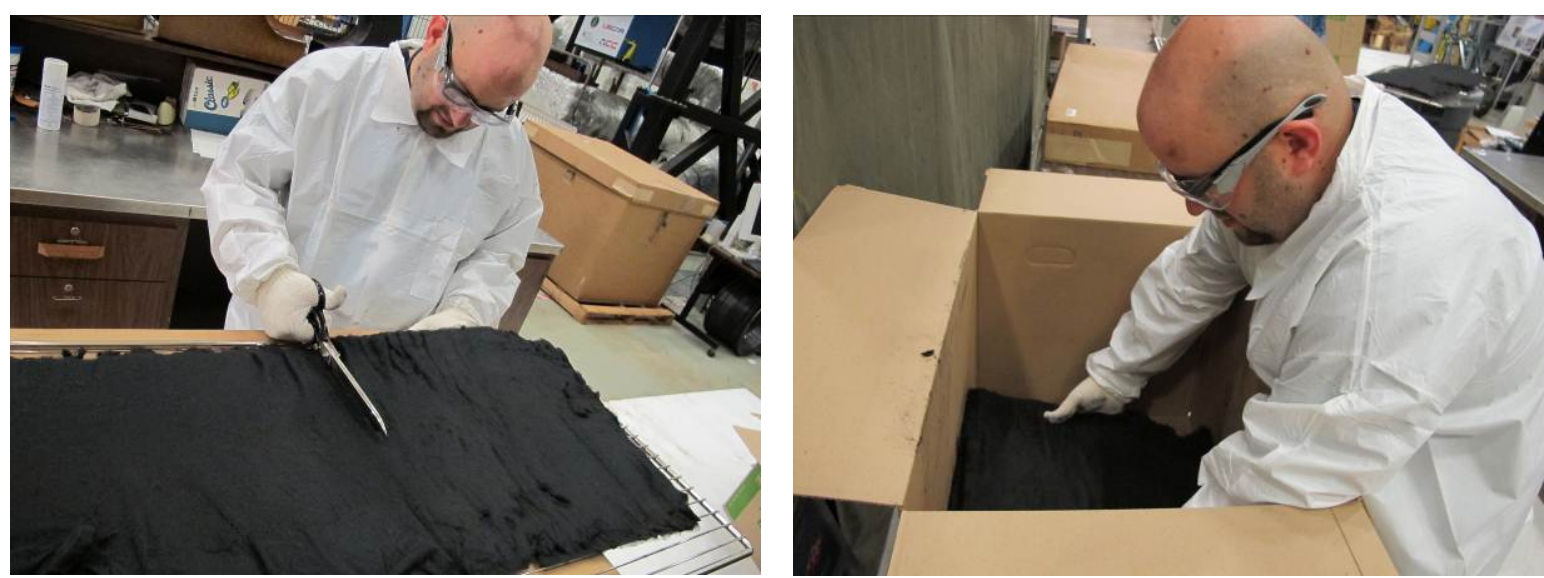

Figure 11. Preparing the stabilized fiber web for shipment to GrafTech.

\subsubsection{Fiber Carbonization}

GrafTech heat treated the stabilized fibers to produce $\sim 40 \mathrm{lb}$ of carbon fibers in a condition for the production of prototype insulation boards. This is the first reported carbonization of lignin fibers at a scale exceeding $\sim 1 \mathrm{lb}$. The carbon fibers were then milled to produce the form needed for prototype fabrication. Milled carbon fibers are shown in Figure 12.

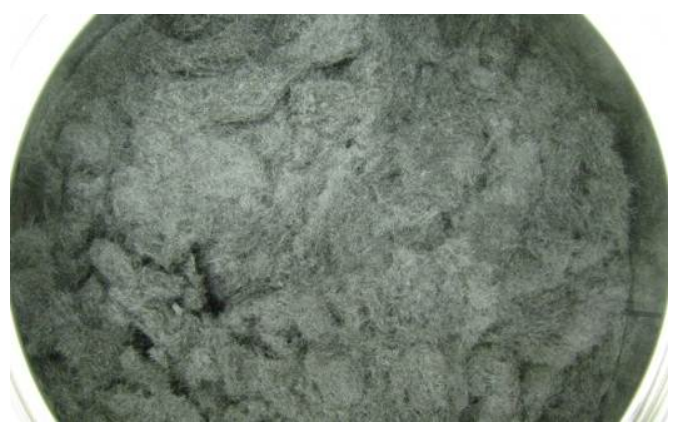

Figure 12. Milled lignin based carbon fiber (Photo by GrafTech). 


\subsubsection{Insulation Prototype Fabrication}

GrafTech fabricated two insulation prototypes, each $~ 18$ " diameter x 10" thick (Figure 13). This is the first reported production of a composite (either functional or structural) made from LBCF, at the cubic foot scale.

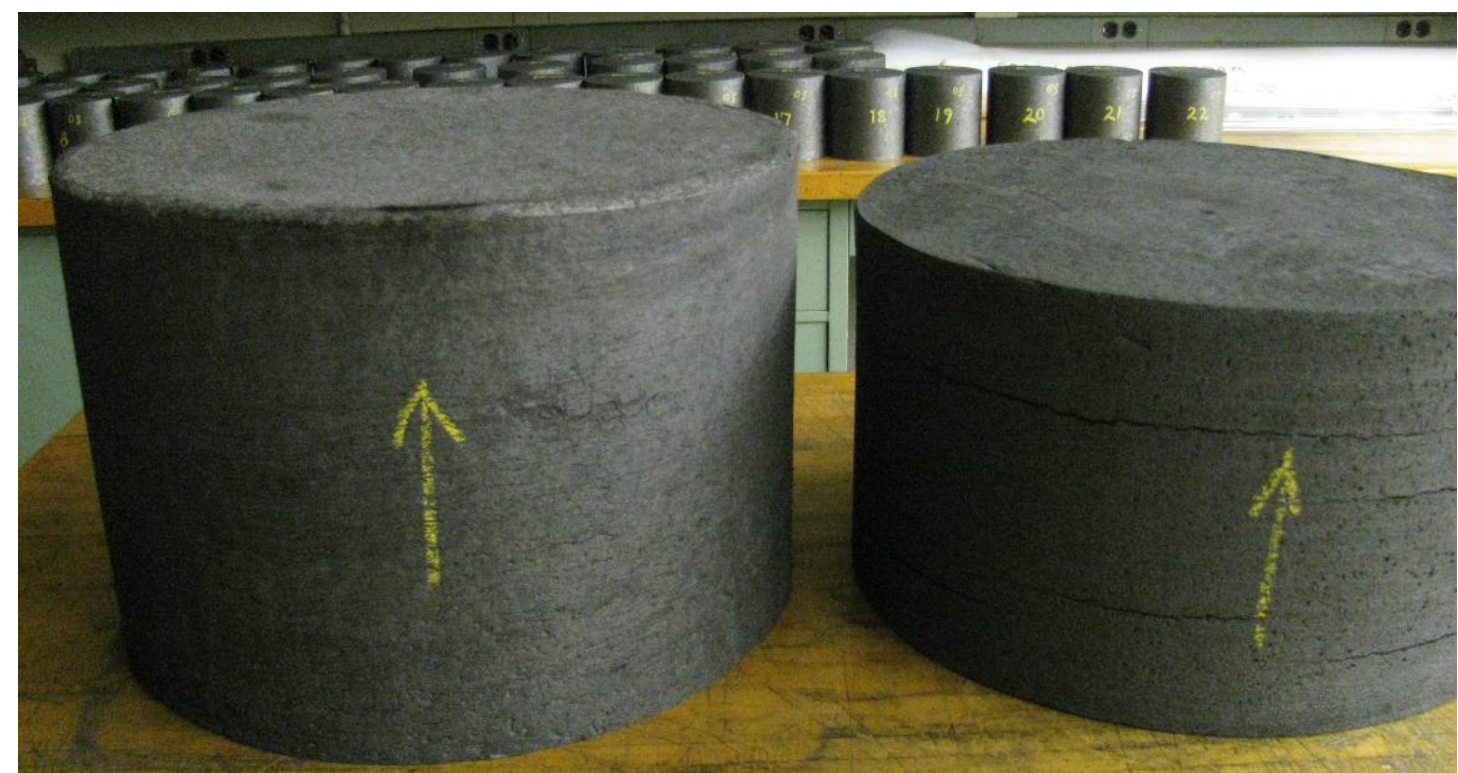

Figure 13. 18” diameter thermal insulation prototypes fabricated from LBCF (GrafTech photo).

\subsection{PERFORMANCE EVALUATION}

GrafTech measured the key performance parameters of the insulation prototypes and found them to be within acceptable ranges and comparable to those of its current commercial product. The key data is summarized in Table 1.

Table 1. LBCF GRI ${ }^{\mathrm{TM}}$ properties vs. commercial product and process limits

\begin{tabular}{|l|c|c|c|c|c|c|c|c|c|}
\hline & $\begin{array}{c}\text { Bulk } \\
\text { density } \\
\text { g/cc }\end{array}$ & \multicolumn{2}{|c|}{$\begin{array}{c}\text { Thermal } \\
\text { conductivity } \\
\text { W/m-K }\end{array}$} & \multicolumn{2}{|c|}{$\begin{array}{c}\text { Compressive } \\
\text { strength } \\
\text { MPa }\end{array}$} & \multicolumn{2}{|c|}{$\begin{array}{c}\text { Flexural } \\
\text { strength } \\
\text { MPa }\end{array}$} & \multicolumn{2}{|c|}{$\begin{array}{c}\text { Specific } \\
\text { Resistance } \\
\mu \Omega-m\end{array}$} \\
\hline & & WG $^{*}$ & AG & WG & AG & WG & AG & WG & AG \\
\hline LBCF 1 & 0.17 & 0.33 & 0.16 & 0.90 & 0.41 & 1.08 & 0.15 & 890 & 4900 \\
\hline LBCF 2 & 0.16 & 0.28 & 0.20 & 0.56 & 0.29 & 0.77 & 0.19 & 1200 & 4400 \\
\hline $\begin{array}{l}\text { Commercial } \\
\text { GRI }^{\text {TM }}\end{array}$ & 0.18 & 0.39 & 0.18 & 1.03 & 0.31 & 1.06 & 0.16 & 670 & 4700 \\
\hline
\end{tabular}

*WG - with grain: AG - across grain

Low density and thermal conductivity, but higher strengths and specific resistance are preferred. Both LBCF samples are in the acceptable range for all properties, with some of their properties being better than those of the current commercial product. 
Oxidation resistance, measured as percent weight loss in air at $400{ }^{\circ} \mathrm{C}$, is also comparable at $\sim 0.1 \%$ for LBCF vs. $0.1-0.2 \%$ for typical pitch-based carbon fibers. Additionally, as shown in Figure 14, the LBCF insulation exhibits uniform structure. The cracks in the left image are attributable to an unoptimized curing process, and are considered acceptable at the current technology readiness level.
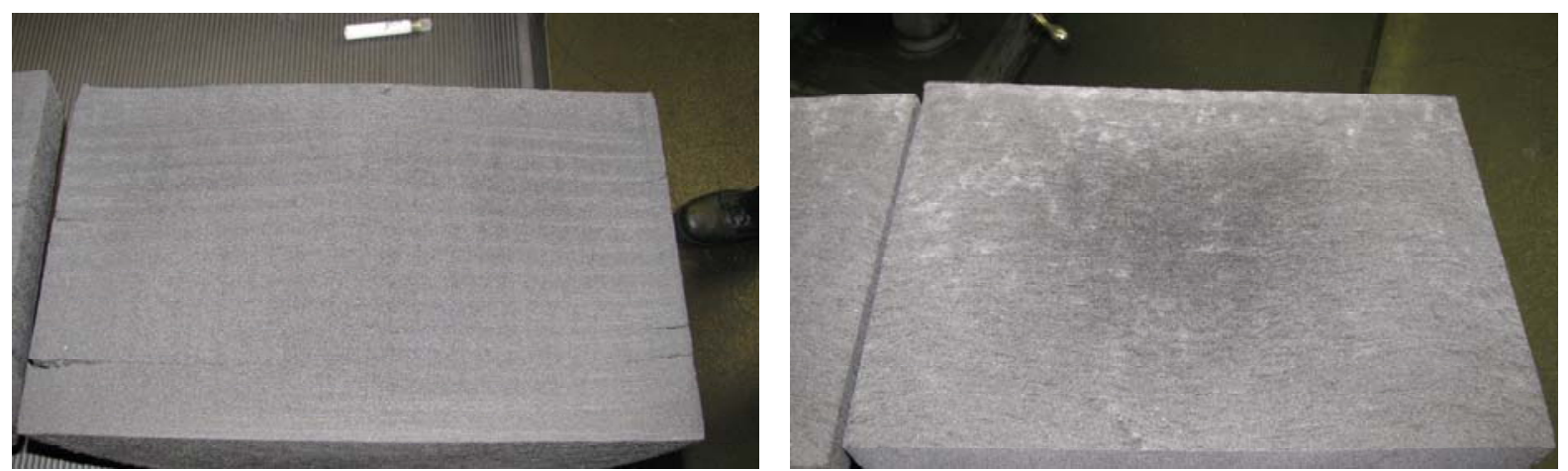

Figure 14. LBCF insulation sections showing uniform structure.

Finally, the filament diameter (Figure 15) of the LBCF insulation is also acceptable. The mean filament diameter, at $\sim 12 \mu \mathrm{m}$, is slightly finer than $15 \mu \mathrm{m}$ diameter that is typically observed for isotropic pitchbased fibers.

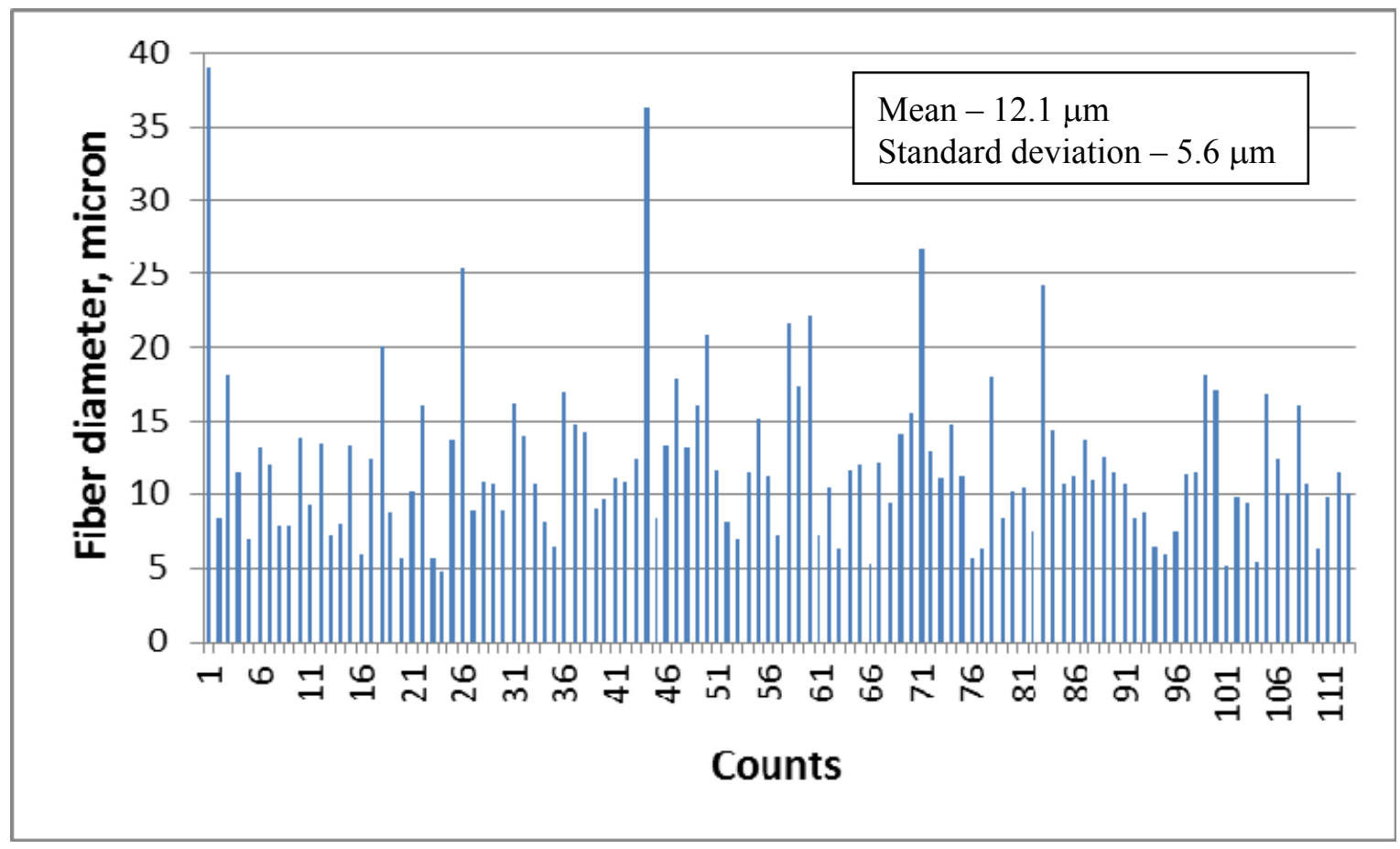

Figure 15. LBCF filament diameter statistics. 


\section{BENEFITS ASSESSMENT}

This project exploits the "low-hanging fruit" of the thermal insulation opportunity to create significant, rational demand and deliver early revenue and profitability from lignin based carbon fibers. Thermal insulation and other near-term, relatively modest applications will serve as the spring board to grow the production infrastructure that is needed assure the necessary supply for energy applications with large volume demand and significant impact on U.S. prosperity as well as energy and environmental security. The U.S. benefits are assessed here based on the assumption that the thermal insulation application will be followed by commercial application in graphite electrodes, and in the longer term, semi-structural automotive components. These are approximate estimates based on rules of thumb rather than detailed and rigorous analyses.

The commercialization of lignin-based carbon fibers offers immediate economic impact by recapturing jobs that were previously exported to China. The US economic impact is estimated to be hundreds of jobs within five years, growing to approximately 1,000 jobs by 2020 , and more than 50,000 jobs two decades after the insulation product launch. About $80 \%$ of the estimated jobs are direct manufacturing jobs making carbon fibers or downstream products made from them. Figure 16 shows the estimated US jobs impact.

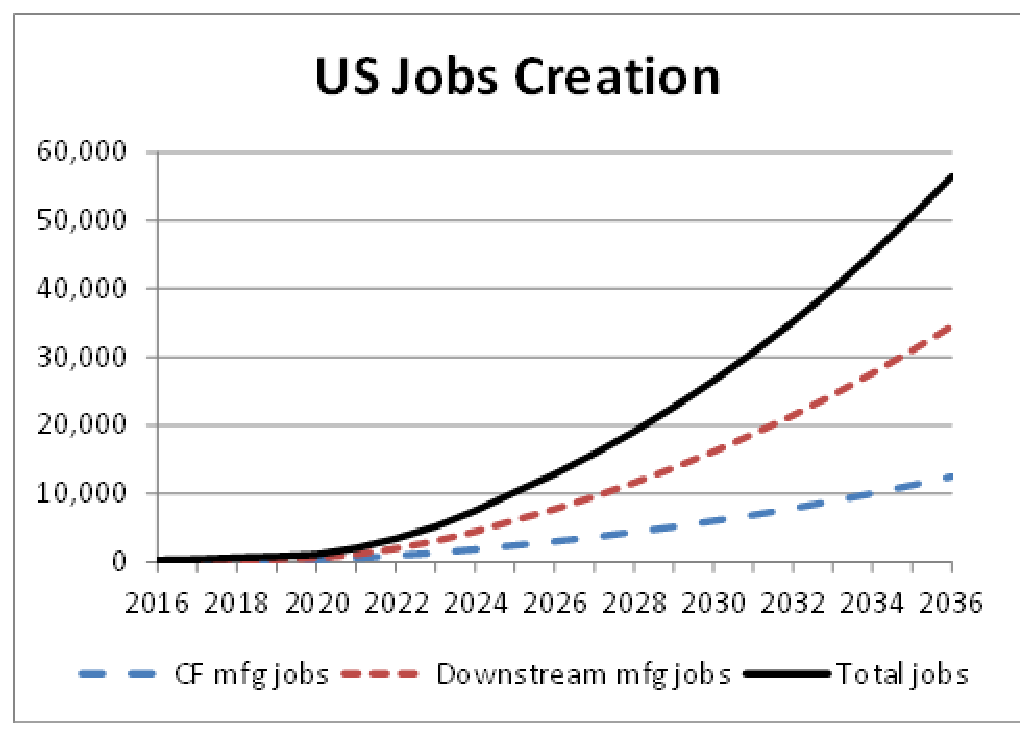

Figure 16. Estimated jobs impact of lignin-based carbon fibers.

The commercialization of LBCF thermal insulation is expected to lead to other applications with very large energy savings potential. Ironically, reinforcing graphite electrodes with carbon fibers is estimated to increase steel manufacturing's energy productivity by about $5 \%$, resulting in energy savings. The potential automotive energy savings is enormous, even when based on the assumption that LBCF will not be used in primary structure (Figure 17). The energy savings result from light weighting of the vehicle; carbon fiber composites can significantly reduce automobile weight with attendant fuel savings of approximately $7 \%$ for every $10 \%$ vehicle weight reduction. ${ }^{8}$ 


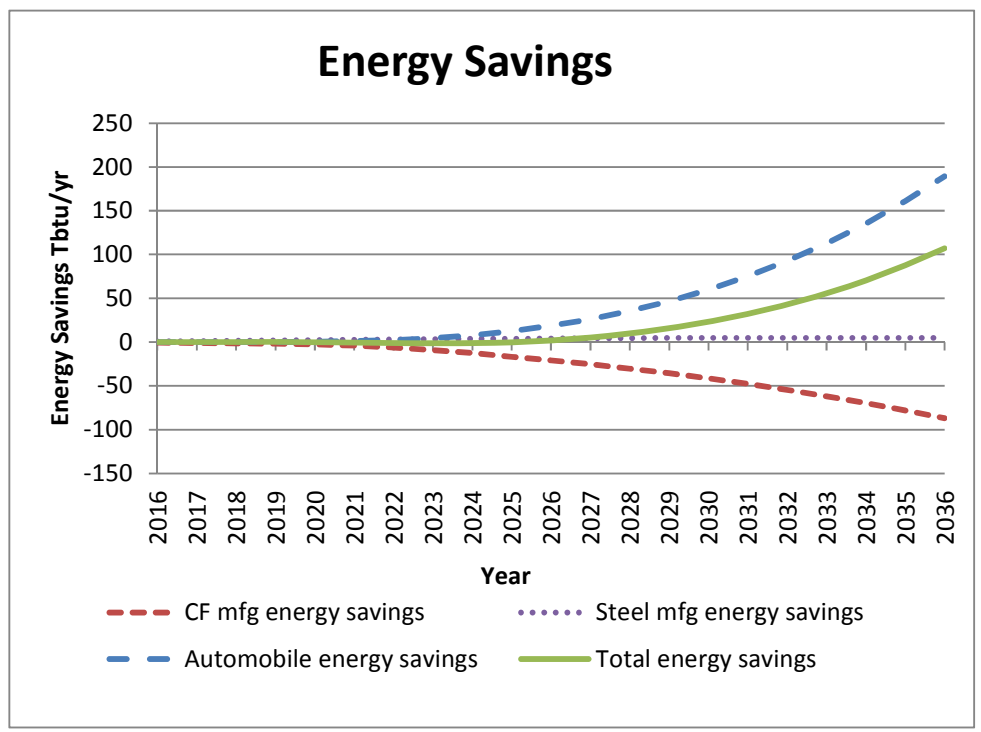

Figure 17. Time profile of US energy savings attributable to lignin-based carbon fibers.

As shown in Figure 18, the net $\mathrm{CO}_{2}$ emission avoidance attributable to low-cost carbon fibers is estimated to exceed 7 million metric tons annually by 2036 . The emission avoidance is almost entirely attributable to reduction of fossil fuel demand due to lower energy demand.

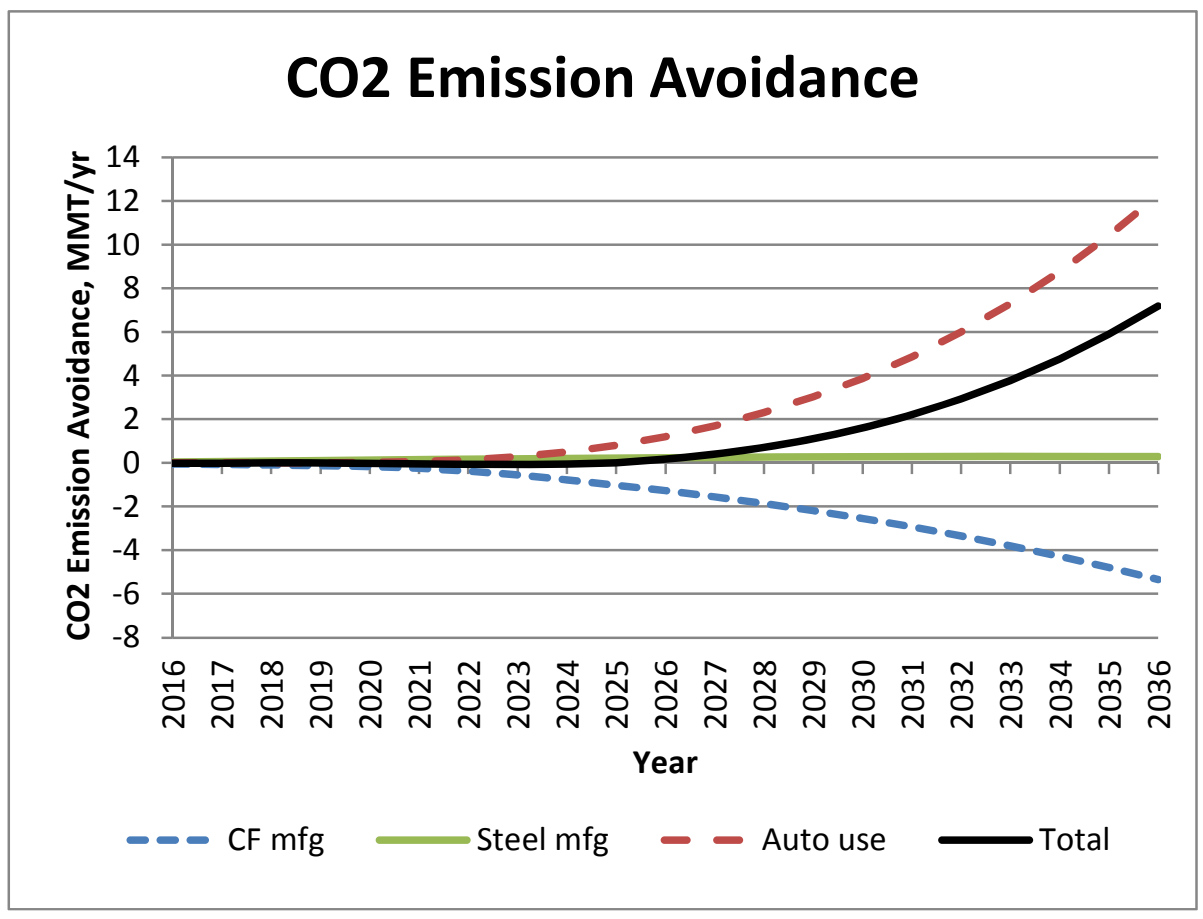

Figure 18. Time profile of $\mathrm{US} \mathrm{CO}_{2}$ emissions avoidance attributable to low-cost carbon fibers. 


\section{COMMERCIALIZATION}

A major advantage of the thermal insulation application is that it is an existing GrafTech product line. It is also a "right-sized" first application, being large enough to justify the investment for a commercial scale LBCF production factory but small enough that the business and technical risks appear to be acceptable and manageable.

\subsection{SCALE REQUIREMENTS}

The estimated sales volume at product launch for the thermal insulation application will require something around $500-1,000$ tons/year of carbon fibers. Accounting for yield in fiber production, the initial lignin requirements are at least 1,000 tons/year and projected growth in markets requiring high temperature thermal insulation would increase the demand by about $10 \mathrm{X}$ over a decade. The business case for LBCF thermal insulation requires that lignin and equipment suppliers must be able to deliver raw materials and equipment at this scale and on this schedule.

\subsection{CURRENT STATE OF THE TECHNOLOGY}

Organosolv pulped, hardwood Alcell ${ }^{\circledR}$ lignin was supplied by Lignol Innovations (Lignol) from a warehoused, legacy inventory. Lignol's current inventory is about 100 tons and its current production capacity is tens of tons annually at most. Lignol plans to scale its technology but has not yet committed the required capital investment for production capacity required to satisfy the scale requirements.

A high level process flow chart is shown in Figure 19. Process scale-up approach and results are documented in section 3.2.

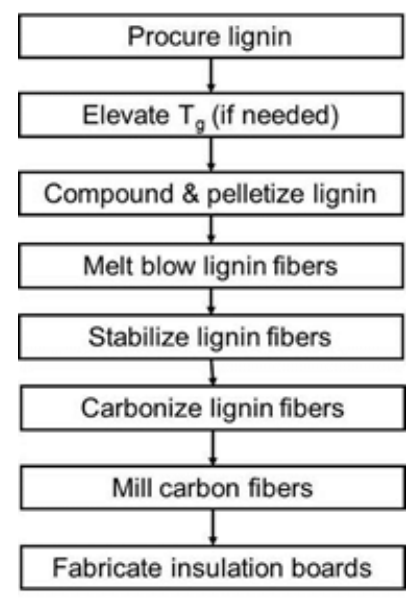

Figure 19. Process flow chart for current technology.

ORNL has estimated the production cost of lignin fibers produced by melt blowing to form a mat which is then stabilized and carbonized by conventional heat treatment. As shown in Figure 20, the estimated production cost is $\$ 4.22 / \mathrm{lb}$ based on the following key assumptions:

- $\$ 0.25 / 1$ burchase price for lignin powder

- No treatment or purification required before compounding

- Compounding and pelletizing required 
- $44 \mathrm{oz} / \mathrm{sq}$ yd $\left(1,500 \mathrm{~g} / \mathrm{m}^{2}\right)$ areal density of melt spun precursor fiber web (based on ConocoPhillips pitch line areal density ${ }^{9}$ )

- Web is packaged and moved between spinning and heat treatment, i.e., not direct-fed

- Conventional heat treatment including high temperature $\left(>1,000^{\circ} \mathrm{C}\right)$ carbonization and posttreatments, no creel or stretching equipment

- 2-hour stabilization time

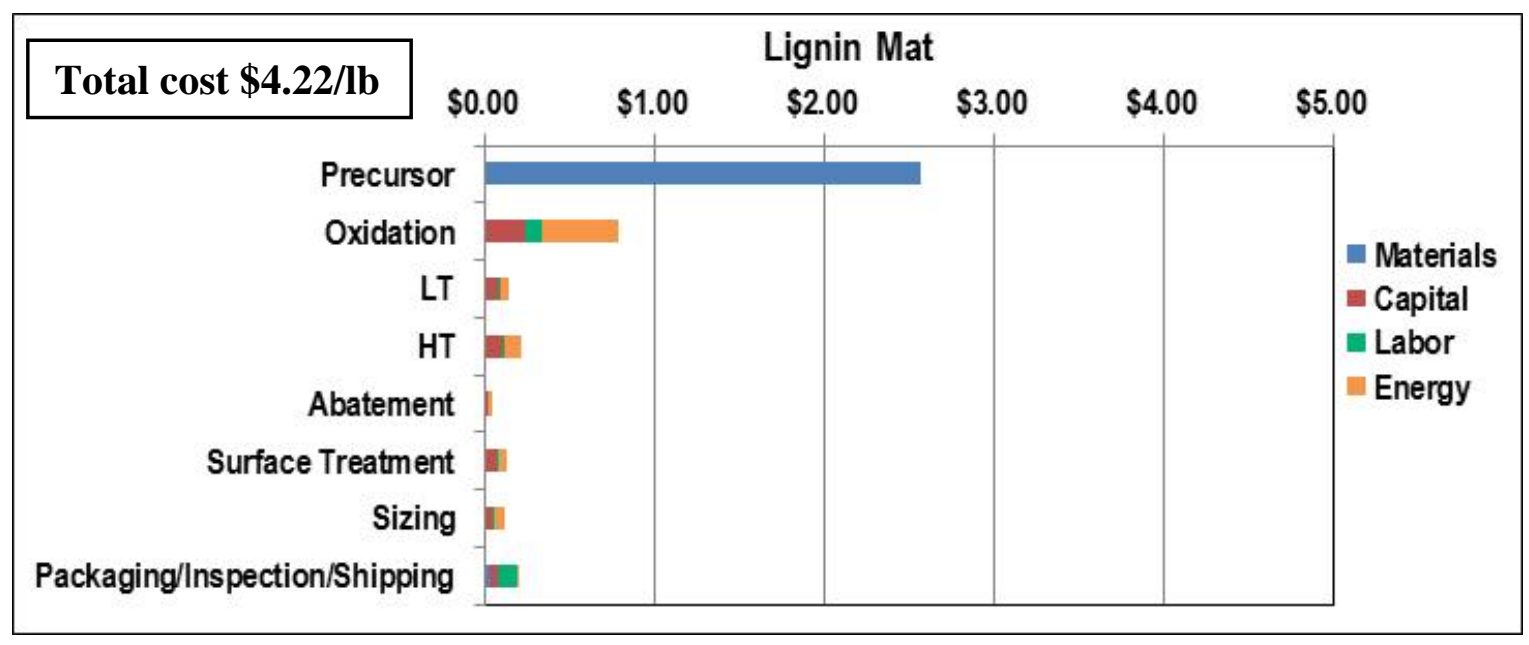

Figure 20. Estimated production cost of lignin carbon fiber web.

- $45 \%$ chemical yield in heat treatment

- 6,250 ton/year carbon fiber production line capacity with matched spinning capacity

These key assumptions range represent a reasonable balance of what is currently known and likely to be achievable. Stabilization time is one of the critical assumptions; 2 hours was used based on laboratory data in which the lignin received a nonscalable vacuum bake before compounding. At pilot scale, without the vacuum bake, the stabilization time is $\sim 100$ hours. Recent data from ORNL internally funded work has demonstrated that $\sim 10 \mathrm{hr}$ stabilization time is achievable with a scalable treatment that replaces the vacuum bake. A simple, rule-of-thumb "scaling law" can be used to approximately estimate how the stabilization time will impact overall cost. In this estimate, if throughput is increased by a factor X (as a result of factor $\mathrm{X}$ decrease in stabilization time and appropriate resizing of other conversion unit operations), the unit conversion cost is $\mathrm{C}_{\mathrm{r}}{ }^{*} \mathrm{X}^{\mathrm{n}-1}$ where $\mathrm{n}$ is the scaling exponent and $\mathrm{C}_{\mathrm{r}}$ is the unit conversion cost at the reference scale. Figure 21 shows the results of that analysis, where the assumed scaling exponent is 0.7 on the conversion cost with the precursor cost contribution held constant ${ }^{10}$. Since the reference stabilization time is 2 hours, the estimated cost at 100 hours is highly suspect but the trend is probably reasonable up to $10-20$ hours and suggests that stabilization time on the order of 10 hours or less should achieve about $\$ 5 / \mathrm{lb}$ production cost. This delivers a very compelling financial advantage over isotropic pitch fibers. 


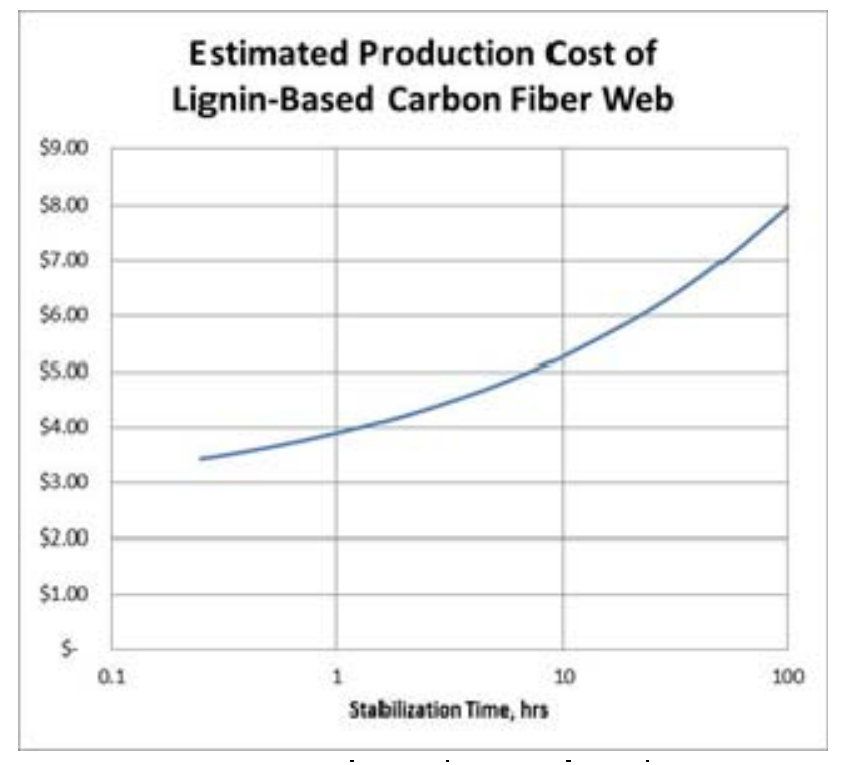

Figure 21. Estimated correlation of production cost with stabilization time.

\subsection{IMPLEMENTATION PATHWAY}

There are two major commercialization barriers that drive the implementation pathway: lignin sourcing and stabilization kinetics.

- A viable business case requires multiple qualified lignin sources that can deliver at scale the necessary cost requirements. To date, work has been with a single source/supplier that currently lacks the financial means to scale.

- High-rate processing must be demonstrated in all unit operations. Currently the processing bottleneck is stabilization at $\sim 100$ hours. Some simple approaches simply move the problem to a different unit operation, e.g., increase stabilization kinetics at the penalty of slower precursor fiber production.

The implementation pathway to address these issues is summarized in Table 2 and discussed below.

Table 2. Summary of Implementation Pathway

\begin{tabular}{|l|l|}
\hline \multicolumn{1}{|c|}{ Need } & \multicolumn{1}{c|}{ Pathway } \\
\hline Multiple lignin sources $>10 \mathrm{k}$ tpy & Qualify lignin sources that are scaling to $>10 \mathrm{k}$ tpy \\
\hline Clean lignin & Evaluate scalable purification methods \\
\hline Fast stabilization & Process development \&/or chemical modification \\
\hline $\begin{array}{l}\text { Continuous process qualified for multiple lignin } \\
\text { sources }\end{array}$ & Process development \&/or chemical modification \\
\hline Carbon fiber manufacturer & $\begin{array}{l}\text { GrafTech will secure its supply chain via purchase } \\
\text { agreements }\end{array}$ \\
\hline
\end{tabular}

The development and qualification of multiple lignin sources that can deliver at required cost, quality, and scale is perhaps the most significant step required for commercial implementation. Today, there is no commercial lignin source in the world that can deliver at the required scale and quality. Fortunately there are a few pulp producers and bio-refiners that are starting down the pathway toward commercial scale 
lignin production. Qualification of multiple sources appears to be within reach and will require the production and evaluation of thermal insulation prototypes and/or commercial boards from each candidate lignin source.

The "reference" Alcell ${ }^{\circledR}$ lignin is a relatively pure lignin that melt spins well. It is likely that at least some of the candidate lignins that will be evaluated for qualification will not meet purity specifications. Therefore, it may also be necessary to evaluate and qualify one or more purification technologies that are sufficiently mature that they can rapidly be commercially implemented. It is also likely that some lignins may require pre-treatment, chemical modification, or blending with additives to render them melt spinnable.

As previously noted, the "reference" Alcell ${ }^{\circledR}$ lignin stabilizes very slowly, requiring $\sim 100$ hours. Most hardwood lignins are likely to suffer from slow stabilization kinetics. We have demonstrated the ability to accelerate kinetics at the lab scale to achieve 2-hour stabilization. This was accomplished by "devolatilization" via vacuum baking prior to spinning. Vacuum baking is not a scalable technique, so we must demonstrate a scalable method to accelerate stabilization. Preliminary data from a stirred devolatilization reactor indicates $\sim 10 \mathrm{X}$ faster stabilization at the $\sim 1$-lb batch scale. It will be necessary to demonstrate this or some other method for stabilizing in $<10$ hours at the semi-production scale of order $100 \mathrm{lb} / \mathrm{hr}$ to provide confidence in achieving acceptable stabilization time at commercial scale.

It is necessary to achieve a fully integrated, high-rate, robust production process. One method of increasing the stabilization rate is by using softwood lignin, but this then has a major negative impact on melt spinning, which simply moves cost to a different unit operation. A key objective is to develop a production process in which all unit operations are high-rate, robust, and well integrated with cost relatively distributed among them.

Finally, a carbon fiber manufacturer is needed. GrafTech is evaluating potential carbon fiber suppliers and will secure its supply chain via purchase agreements.

\subsection{PLAN EXECUTION}

This commercialization plan will be executed in accordance with GrafTech's new business development process. This is a stage-gated process with five stages separated by gates. Each stage can be considered a project phase, with each gate being a formal go/no-go decision point requiring specific information and deliverables to secure a "go" decision. This process, with key outputs from each stage, is illustrated in Figure 22. 


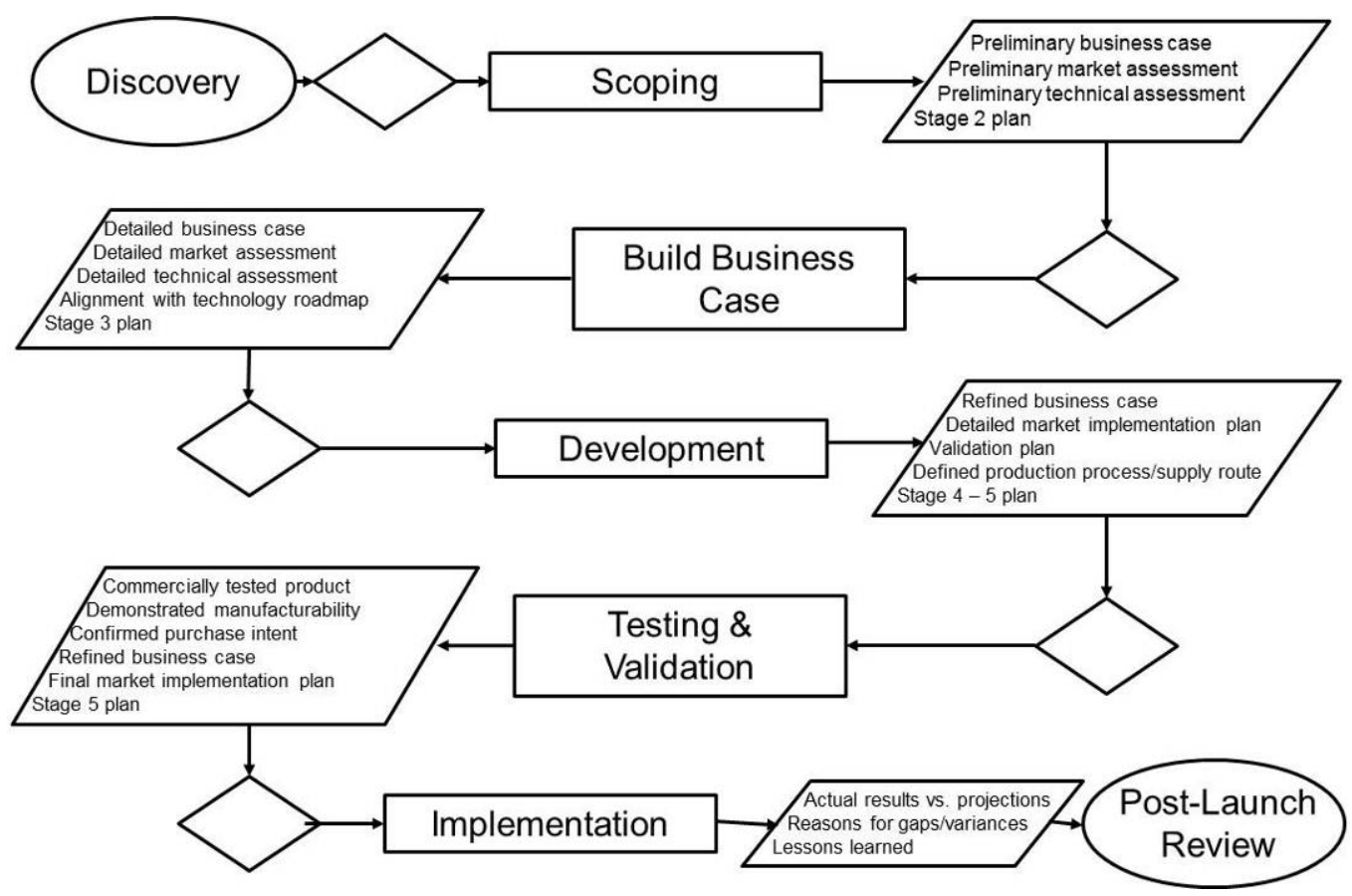

Figure 22. Summary flow chart of new business development process

This project is nearing the completion of stage 2, "Build Business Case". The primary project focus has been the technical assessment, which has largely been conducted experimentally. The successful production and evaluation of prototypes complete the stage 2 technical assessment. Other assessments and the stage 3 plan are partially developed and must also be completed to secure a "go" decision by GrafTech's leadership at Gate 3.

Many of the deliverables in the business development process, including the description of market, detailed market assessment, business case, competition assessment, detailed technical assessment, market segmentation by material properties, production plan, planned investment, etc. are GrafTech proprietary information that are withheld from publication.

\subsection{COMMERCIALIZATION SCHEDULE}

Multiple scalable lignin sources will be qualified in 2013. Multiple tons of LBCF GRI ${ }^{\mathrm{TM}}$ will be manufactured and field tested by customers in 2014. Supply chain agreements will also be negotiated in 2014. Supply chain agreements will be signed upon confirmation of customer purchase intent, and LBCF $\mathrm{GRI}^{\mathrm{TM}}$ will be introduced as a commercial product as soon thereafter as fiber production capabilities can be constructed and commissioned.

All dates are contingent on success in passing gates and securing funding. 


\section{ACCOMPLISHMENTS}

- $\quad$ LBCF thermal insulation prototypes were produced at two scales with both meeting performance evaluation criteria

- During production of the insulation prototypes, ORNL and GrafTech demonstrated lignin compounding/pelletization, fiber production, heat treatment, and compositing at scales far surpassing those previously demonstrated in LBCF R\&D or production.

$>$ First lignin pellet production, meeting fiber extrusion requirements, at scale $>10 \mathrm{lb}$

$>$ First lignin fiber production at scale $>10 \mathrm{lb}$

$>$ First production of melt blown web from lignin

$>$ First lignin fiber stabilization at scale $>1 \mathrm{lb}$

$>$ First lignin fiber carbonization at scale $>1 \mathrm{lb}$

$>$ First production of LBCF composite articles at $1 \mathrm{ft}^{3}$ scale

- Seven invention disclosures by ORNL (filing decisions pending)

Table 3. ORNL Invention Disclosures

\begin{tabular}{|c|l|l|c|}
\hline $\begin{array}{c}\text { ID / } \\
\text { Patent \# }\end{array}$ & \multicolumn{1}{|c|}{ Inventor } & \multicolumn{1}{|c|}{ Title } & Status \\
\hline 2778 & Nunnery et. al. & High speed melt spinning of multi-filament lignin & $\begin{array}{c}\text { Disclosed } \\
12-30-11\end{array}$ \\
\hline 2779 & Nunnery et. al. & Compounding and pelletization of lignin & $\begin{array}{c}\text { Disclosed } \\
12-30-11\end{array}$ \\
\hline 2780 & Nunnery et. al. & $\begin{array}{l}\text { Novel compositions for lignin-based carbon fiber } \\
\text { formation optimization }\end{array}$ & $\begin{array}{c}\text { Disclosed } \\
12-30-11\end{array}$ \\
\hline 2781 & Nunnery et. al. & High-rate Melt-blown Processing of Lignin Fibers & $\begin{array}{c}\text { Disclosed } \\
12-30-11\end{array}$ \\
\hline 2782 & Nunnery et. al. & $\begin{array}{l}\text { Isotropic Lignin-Based Carbon Fibers with Low } \\
\text { Transport Properties }\end{array}$ & $\begin{array}{c}\text { Disclosed } \\
12-30-11\end{array}$ \\
\hline 2891 & $\begin{array}{l}\text { Nunnery \& } \\
\text { Webb }\end{array}$ & Lignin-based hollow carbon fibers & $\begin{array}{c}\text { Disclosed } \\
6-27-12\end{array}$ \\
\hline 2892 & $\begin{array}{l}\text { Nunnery \& } \\
\text { Webb }\end{array}$ & $\begin{array}{l}\text { Improved lignin handling for carbon fiber } \\
\text { manufacture }\end{array}$ & $\begin{array}{c}\text { Disclosed } \\
6-27-12\end{array}$ \\
\hline
\end{tabular}

- Four invention disclosures by GrafTech (filing decisions pending)

- Three ORNL post-doctoral researchers that worked on this project have secured rewarding private sector employment 


\section{CONCLUSIONS}

The key conclusions of this work are that LBCF thermal insulation performance at the prototype scale is similar to that of commercial thermal insulation made from pitch-based carbon fibers. Technical feasibility for the performance of LBCF thermal insulation has been demonstrated. Several "world record" scaling milestones were achieved to demonstrate this performance. Technology commercialization offers significant potential benefit for both the U.S. and the industrial value chain. Further detailed development, scaling, and qualification are now needed to realize the first commercial application of LBCF. 


\section{RECOMMENDATIONS}

Further detailed development, scaling, and qualification are still needed to realize the first commercial application of LBCF. The ORNL-GrafTech partnership should continue efforts to commercialize lowcost lignin-based carbon fibers for the thermal insulation application described in this project. Commercialization efforts should be prioritized in the two key needs areas identified here; reduction of the stabilization time for carbon fibers and establishing multiple industrial-scale sources of lignin suitable for processing.

The Alcell ${ }^{\circledR}$ lignin used in this study stabilizes very slowly, requiring $\sim 100$ hours. Most hardwood lignins are likely to suffer from slow stabilization kinetics. We have demonstrated the ability to accelerate kinetics at the lab scale to achieve 2-hour stabilization. This was accomplished by "devolatilization" via vacuum baking prior to spinning. Vacuum baking is not a scalable technique, so we must demonstrate a scalable method to accelerate stabilization. Preliminary data from a stirred devolatilization reactor indicates $\sim 10 \mathrm{X}$ faster stabilization at the $\sim 1$-lb batch scale. It will be necessary to demonstrate this or some other method for stabilizing in $<10$ hours at the semi-production scale of order $100 \mathrm{lb} / \mathrm{hr}$ to provide confidence in achieving acceptable stabilization time at commercial scale. One other method of increasing the stabilization rate is by using softwood lignin, but this then has a major negative impact on melt spinning, which simply moves cost to a different unit operation. A key objective for commercialization is to develop a production process in which all unit operations are high-rate, robust, and well integrated with cost relatively distributed among them.

The development and qualification of multiple lignin sources that can deliver at required cost, quality, and scale is perhaps the most significant step required for commercial implementation. Today, there is no commercial lignin source in the world that can deliver at the required scale and quality. Fortunately there are a few pulp producers and bio-refiners that are starting down the pathway toward commercial scale lignin production. Qualification of multiple sources appears to be within reach and will require the production and evaluation of thermal insulation prototypes and/or commercial boards from each candidate lignin source.

It is likely that at least some of the candidate lignins that will be evaluated for qualification will not meet purity specifications. Therefore, it may also be necessary to evaluate and qualify one or more purification technologies that are sufficiently mature that they can rapidly be commercially implemented. It is also likely that some lignins may require pre-treatment, chemical modification, or blending with additives to render them melt spinnable. 


\section{REFERENCES}

1 C. D. Warren, "Lower Cost Carbon Fiber in High Volumes for $21^{\text {st }}$ Century Industries", Presented at and published in the proceedings of the SPE Automotive Composites Conference \& Exhibition, Detroit, MI, 13-15 September 2011

2 Chris Red, "2012 Global Market for Carbon Fiber Composites," presented at Carbon Fibers 2012, La Jolla, CA, 4 - 6 December 2012

3 Chuck Kazmierski, “Global Composites Industry: Poised for Growth”, presented at Composites 2012, Las Vegas, NV, 21 - 23 February 2012

4 Peter Axegård, "Trends in Pulp Mill Biorefining", seminar presented at Oak Ridge National Laboratory, Oak Ridge, TN, 31 January 2012

5 Sujit Das, "Cost Modeling of Alternative Carbon Fiber Manufacturing Technologies - Baseline Model Demonstration," presented to Advanced Manufacturing and Vehicle Technologies staff, Washington, DC, 5 April 2012

6 Japanese patents

7 C. D. Warren, "Low Cost Carbon Fiber Development," DOE Vehicle Technologies Program Lightweighting Materials 2011 Annual Report

8 Lynette W. Cheah, "Cars on a Diet: The Material and Energy Impacts of Passenger Vehicle Weight Reduction in the U.S.”, Massachusetts Institute of Technology Ph.D. Thesis, Sept 2010

9 Mark Southard, private communication, March 2013

${ }^{10}$ Scaling factor 0.7 recommended for carbon fiber conversion equipment by an industry consultant 